\title{
Next Generation Vaccines
}

\author{
Oral Plenary Abstracts
}

ISPPD-0121

Next Generation Vaccines

\section{A PHASE 1 STUDY TO ASSESS THE SAFETY, TOLERABILITY AND IMMUNOGENICITY OF INACTIVATED NON- ENCAPSULATED STREPTOCOCCUS PNEUMONIAE WHOLE CELL VACCINE}

M. Alderson ${ }^{1}$, R. Malley ${ }^{2}$, P. Anderson ${ }^{3}$, C. Thompson ${ }^{2}$, R. Morrison ${ }^{4}$, D. Briles ${ }^{5}$, J. King ${ }^{5}$, D. Goldblatt ${ }^{6}$, N. Green $^{6}$, J. Hural ${ }^{7}$, J. Flores ${ }^{8}$, A. Tate ${ }^{1}$, J. Maisonneuve ${ }^{1}$, C. Keech ${ }^{1}$

${ }^{1}$ Vaccine Development, Path, Seattle, USA; ${ }^{2}$ Division of Infectious Diseases, Boston Children's Hospital, Boston, USA; ${ }^{3}$ Division of Infectious Diseases, Harvard Medical School, Boston, USA; ${ }^{4}$ Clinical Development, Comprehensive Clinical Development, Tacoma, USA; ${ }^{5}$ Microbiology, University of Alabama at Birmingham, Birmingham, USA; ${ }^{6}$ Institute of Child Health, University College London, London, United Kingdom; ${ }^{7} \mathrm{HIV}$ Vaccine Trials Network, Fred Hutchinson Cancer Research Center, Seattle, USA; ${ }^{8}$ Vaccine Development, Path, Washington DC, USA

Background and aims: There is a need for broadly protective pneumococcal vaccines that are affordable for developing countries where the highest burden of pneumococcal disease occurs. SPWCV is an investigational vaccine that contains killed whole cells from a non-encapsulated strain of Streptococcus pneumoniae. Preclinical studies have demonstrated protection against both nasopharyngeal carriage (T-cell mediated) and invasive disease (antibody mediated). The aim of this randomized, double blind, placebo controlled Phase 1 study was to assess the safety, tolerability and immunogenicity of SPWCV formulated with aluminum hydroxide (wSP) in healthy adults. Methods: Forty two subjects were randomized into 3 dose cohorts to receive 100, 300, or $600 \mu \mathrm{g}$ of wSP, or placebo (saline). Subjects received 3 doses at 4 week intervals. Post vaccination assessments included solicited reactogenicity events through day 7 after each dose and adverse events through D84. Subjects were followed for antibody responses and peripheral blood mononuclear cell cytokine responses to pneumococcal antigens.

Results: wSP was safe and well tolerated. Reactogenicity was acceptable and no untoward safety signals were observed. WSP elicited significant IgG responses to pneumococcal antigens, including PspA and pneumolysin, as measured by a variety of immunoassays, including ELISA and Meso Scale Discovery (MSD) multiplex assay. Functional antibody responses were detectable by either passive transfer of protection to mice or elicitation of pneumolysin toxin neutralizing antibodies. Significant increases in T-cell cytokine responses, including IL-17, were seen among subjects receiving the $600 \mu \mathrm{g}$ dose level of wSP.

Conclusion: wSP is safe and well tolerated, eliciting pneumococcal antigen-specific antibody and T-cell cytokine responses.

No conflict of interest

ISPPD-0551

Next Generation Vaccines

\section{IMMUNOGENICITY OF PRIMARY VACCINATION WITH AN INVESTIGATIONAL PROTEIN-BASED PNEUMOCOCCAL VACCINE IN INFANTS IN EUROPE: A PHASE II RANDOMIZED TRIAL}

\author{
R. Prymula' ${ }^{1}$, L. Szenborn ${ }^{2}$, S.A. Silfverdal ${ }^{3}$, J. Wysocki ${ }^{4}$, P. Albrecht ${ }^{5}$, N. François ${ }^{6}$, A. Gardev ${ }^{6}$, D. Borys ${ }^{6}$ \\ ${ }^{1}$ Directorate, University Hospital Hradec Králové and Medical Faculty Charles University, Hradec Králové, Czech Republic; ${ }^{2}$ Medical Univer- \\ sity Wroclaw, Wroclaw, Poland; ${ }^{3}$ Umeå University, Umeå, Sweden; ${ }^{4}$ University School of Medical Sciences \& Regional Medical Center for Moth- \\ er and Child, Poznan, Poland; ${ }^{5}$ Medical University of Warsaw, Warsaw, Poland; ${ }^{6}$ GlaxoSmithKline Vaccines, Wavre, Belgium
}

Background and Aims: Immunogenicity of 2 formulations of an investigational pneumococcal vaccine containing $10 \mu \mathrm{g}$ (PHiD-CV/dPly/PhtD-10) or 30 $\mathrm{g}$ (PHiD-CV/dPly/PhtD-30) of each of the highly conserved pneumococcal proteins pneumolysin toxoid (dPly) and histidine-triad protein $\mathrm{D}$ (PhtD), combined with polysaccharide conjugates of 10 -valent pneumococcal non-typeable Haemophilus influenzae protein D-conjugate vaccine (PHiD-CV, GlaxoSmithKline Vaccines) was assessed in infants in Europe.

Methods: In this phase II, multicenter, observer-blind study (NCT01204658), healthy 6-14-week-old infants were 1:1:1:1-randomized to receive primary and booster vaccination (at 2/3/4/12-15 months of age) with PHiD-CV/dPly/ PhtD-10, PHiD-CV/dPly/PhtD-30, PHiD-CV or 13-valent pneumococcal CRM ${ }_{17}$-conjugate vaccine (13vCRM, Wyeth LLC), each co-administered with DTPa-HBV-IPV/Hib. Immune responses to dPly, PhtD, pneumococcal serotypespecific polysaccharides and protein $D$ were evaluated, and responses to the different dPly and PhtD doses were compared (secondary objectives). Preliminary results 1 month post-primary vaccination are presented here. Results: Superiority of PHiD-CV/dPly/PhtD-30 versus PHiD-CV/dPly/PhtD-10 was demonstrated: upper limit of 95\% confidence interval for geometric mean antibody concentration (GMC) ratio (PHiD-CV/dPly/PhtD-10 over PHiD-CV/ dPly/PhtD-30) was $<1$ for Ply (0.98) and PhtD (0.94). Post-primary Ply and PhtD GMCs were substantially higher in PHiD-CV/dPly/PhtD-10 and PHiD-CV/dPly/PhtD-30 than in PHiD-CV and 13vCRM recipients. Pneumococcal polysaccharide and protein $D$ antibody responses were in similar ranges after PHiD-CV/dPly/PhtD-10, PHiD-CV/dPly/ PhtD-30 and PHiD-CV primary vaccination (Table).

Conclusion: Primary vaccination with PHiD-CV/dPly/PhtD-10 and PHiD-CV/dPly/PhtD-30 induced robust immune 
responses to all vaccine antigens. Combining dPly and PhtD with PHiD-CV did not interfere with post-primary immune responses to pneumococcal conjugates or protein D.

Funding: GlaxoSmithKline Biologicals SA

\begin{tabular}{|c|c|c|c|c|}
\hline Amigen & 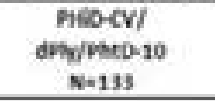 & 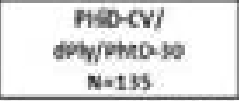 & $\begin{array}{l}\text { mocv } \\
\text { N-13? }\end{array}$ & $\begin{array}{l}32 \mathrm{Non} \\
N-134\end{array}$ \\
\hline \multicolumn{5}{|c|}{ s zat off or tereshold } \\
\hline \multicolumn{5}{|c|}{ 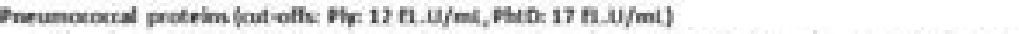 } \\
\hline$\underset{\text { mito }}{\text { mit }}$ & $\begin{array}{l}300(972-100) \\
100(972-100)\end{array}$ & $\begin{array}{l}100(973-100) \\
100(973-100)\end{array}$ & $\begin{array}{l}100(973-100 \mid \\
100|973-100|\end{array}$ & $\begin{array}{l}100(973-100 \mid \\
100(973-100 \mid\end{array}$ \\
\hline \multicolumn{5}{|c|}{ 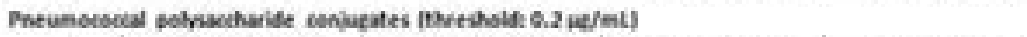 } \\
\hline 1 & $99.2(95.9-100)$ & $98.5(945-988)$ & $94.5(947.998)$ & $97.4(93.6-99.5)$ \\
\hline 4 & $98.5(94.6-99.8)$ & $99.2(959-100)$ & $97.7(935-99.5)$ & $97.0[92.5-99.2]$ \\
\hline $\mathbf{s}$ & at.s $(947-94 \mathrm{~s})$ & ท. $(25$ s-100) & n.s $(205-100)$ & $66.3(915-448)$ \\
\hline EB & $72.5(540-80.91$ & $73.6155 .2-3101$ & $72.9(545-50.3)$ & $75.4[57.2-82.4]$ \\
\hline$w$ & $99.2(958-100$ ) & $99.2(95.8-100)$ & $93.3(95.3-100)$ & $97.8(93.6-995)$ \\
\hline $\mathbf{w}$ & $99.2(95.9-100)$ & $9.3(959-100)$ & $97.8(937-995)$ & $97.0(92.5-99.2)$ \\
\hline 14 & $90.2(95.9-100)$ & $100(973-160)$ & $100(97.3-100)$ & $97.0(225-92)$ \\
\hline 1ac: & as.s (94 7-95.8) & m.2 (959-100) & $97.5(936-995)$ & $97.0(02.3-9.2)$ \\
\hline 19 & 9.5 $647-99.80$ & $9.2 \cos 9-100)$ & $100(973-100)$ & $7.0(92.5-52)$ \\
\hline $2 x$ & $84.8(77.5-90.5)$ & $02.7(752-187)$ & $81.0(75.5-889)$ & $91.8(95.8-95.8)$ \\
\hline \multicolumn{5}{|c|}{ Protein D conier proteis (out off. $190 \mathrm{OL} . \mathrm{U} / \mathrm{m}$ ) } \\
\hline & $940.085 .5-97.47$ & $96.3(91.5-98.81$ & $33.4(2) 9 \times 97.01$ & $41.0[32.5 \mathrm{~m}-3.3]$ \\
\hline \multicolumn{5}{|c|}{$\cos$} \\
\hline \multicolumn{5}{|c|}{ Preumosoxed protrim } \\
\hline $\operatorname{mov}_{\text {nis }}$ & $\begin{array}{l}95 \% 1 \text { (3251-10923) } \\
14 \% 5 \text { (1274-1754) }\end{array}$ & $\begin{array}{c}12067 \text { (10583-13754) } \\
1287(1727-2286)\end{array}$ & $\begin{array}{l}460(398-531) \\
524(454-654)\end{array}$ & $\begin{array}{l}\text { In }(409-557) \\
\text { SSS }(47)-651)\end{array}$ \\
\hline \multicolumn{5}{|c|}{ 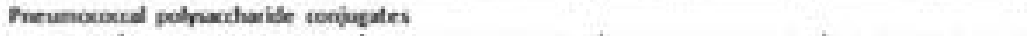 } \\
\hline 1 & $1.56(1.36-1.72)$ & $1.53(2.37-1.54\}$ & $1.49(1.25-1.74)$ & $2.18(1.34-2.57)$ \\
\hline 4 & $2.04(1.74=2.39)$ & $2.12(1.83-2.44)$ & $1.82(1.55-2.14)$ & $2.41(2.04-2.85)$ \\
\hline 5 & $2.45(2.13-2.25)$ & $2.56 \mid 224-2.94\}$ & $2.34(2.00-2.57)$ & $2.78(2.29-339)$ \\
\hline GB & $0.37(0.29-0.45)$ & $0.37 \mid 2.31-0.451$ & $0,40,0.32-0,51]$ & $0.45(0.35-0.56)$ \\
\hline 76 & $2.12(1.36-2.41)$ & $2.28(1.57-2.48)$ & $2.20(1.52-2.50)$ & $2.33(250-3.43)$ \\
\hline $\mathbf{w}$ & $2.53(2.39-2.11)$ & $2.95(1.7)-2.21)$ & $1 . m(1.72-2.30)$ & $2.32(2.96-2.35)$ \\
\hline 14 & $3.60(311-41 \pi)$ & $2.71(3.30-418)$ & $1.41(3.41-4.48)$ & $4.14(1.38-506)$ \\
\hline $18 \mathrm{C}$ & $2.27(1.93-2.67)$ & $2.21(1,87-2.62\}$ & $2.45(2.04-2.95)$ & $2.56(2.14-3.05)$ \\
\hline $19 \pi$ & $4.29(3.54-5.07)$ & $4.1313 .52-4.841$ & $4.51(3.75-5.36)$ & $\mathbf{3 . 4 7}[2.92-413)$ \\
\hline $2 s 4$ & $0.66(654=0.51)$ & $0.6215 .50-0.761$ & $0.67(6.54-0.92)$ & $1.48(1.17-1.87)$ \\
\hline \multicolumn{5}{|c|}{ Protein D carriker protels } \\
\hline & $1136(929-1335)$ & 1393 [1109-1512) & $1539(1254-1882)$ & $150(114-155)$ \\
\hline
\end{tabular}

Conflict of interest

ISPPD-0542

Next Generation Vaccines

\section{A MULTI-COMPONENT PNEUMOCOCCAL PROTEIN VACCINE IS SAFE AND IMMUNOGENIC IN A PHASE 1 RANDOMIZED, PLACEBO-CONTROLLED STUDY}

L. Chang ${ }^{1}$, W.A. Brooks ${ }^{2}$, G. de Bruyn ${ }^{1}$, M. Bologa ${ }^{3}$, R. Hopfer ${ }^{1}$, D. Kirby ${ }^{1}$, X. Sheng ${ }^{1}$, D. Neveu ${ }^{1}$, J. Menezes ${ }^{4}$, M. Ochs ${ }^{5}$, L. Visan ${ }^{5}$, X. DaCosta ${ }^{1}$, T. Yuan ${ }^{3}$, J. Hinds ${ }^{6}$, E. Jordanov ${ }^{1}$

${ }^{1}$ Clinical Development, Sanofi Pasteur, Swiftwater, USA; ${ }^{2}$ International Centre for Diarrhoeal Disease Research, Bangladesh, Dhaka, Bangladesh

${ }^{3}$ Clinical Development, Sanofi Pasteur, Toronto, Canada; ${ }^{4}$ Sanofi Pasteur, Mumbai, India; ${ }^{5}$ Clinical Development, Sanofi Pasteur, Lyon, France

${ }^{6}$ Bacterial Microarray Group, St George's University of London, London, United Kingdom

Background and Aims: Pneumococcal vaccines based on conserved protein antigens offer an alternative to serotype-specific polysaccharide or polysaccharide conjugate vaccines. A Phase I, single-center, randomized, placebo-controlled, observer-blind study (ClinicalTrials.gov identifier NCT01446926) was conducted to assess the safety and immunogenicity of a multi-component pneumococcal protein vaccine candidate.

Methods: The vaccine candidate studied contained recombinant pneumococcal choline-binding protein $A$, recombinant pneumococcal histidine triad protein $D$, and genetically detoxified pneumolysin. The study was conducted in Bangladesh in healthy adults (18-50 years), toddlers (12-13 months), and infants (6 weeks). Adults and toddlers received a single vaccination (high dose of each antigen) or placebo. Infants received 3 doses of aluminum hydroxide adjuvanted formulations containing a low, mid, or high dose of each antigen; an unadjuvanted formulation at mid dose; or placebo at 6, 10, and 14 weeks of age by intramuscular injection. Safety assessments 
included solicited injection site/systemic reactions, unsolicited adverse events (AEs), and serious AEs. Immune responses were measured pre- and post-vaccination by ELISA. This study was funded by Sanofi Pasteur. Results: No related serious AEs were reported. No dose-related increases in frequency, severity, or duration of solicited reactions and no decrease in tolerability with multiple doses or with adjuvantation were seen. Robust immunogenicity was measured in all study populations, with immune responses increasing with ascending dose. For all antigens, post-dose 3 geometric mean concentrations (GMC) were significantly greater than post-dose 2 GMCs.

Conclusions: The vaccine candidate was safe, well-tolerated, and produced robust antibody responses to all 3 antigens, and at all dose levels.

Conflict of interest

ISPPD-0540

Next Generation Vaccines

\section{SAFETY AND IMMUNOGENICITY OF 15-VALENT PNEUMOCOCCAL CONJUGATE VACCINE (PCV15) COMPARED TO PCV13 IN HEALTHY OLDER ADULTS}

C.P. Andrews ${ }^{1}$, S. Folkerth ${ }^{2}$, R. Rupp ${ }^{3}$, D. Greenberg ${ }^{4}$, S. Ermlich ${ }^{5}$, R.D. McFetridge ${ }^{5}$, J. Hartzel ${ }^{6}$, R.D. Marchese ${ }^{5}$, J.E. Stek ${ }^{7}$, C. Abeygunardawana ${ }^{8}$, L. Musey ${ }^{9}$

${ }^{1}$ Clinical Research, Diagnostics Research Group, San Antonio TX, USA; ${ }^{2}$ Clinical Research, Clinical Research Center of Nevada, Las Vegas NV, USA

${ }^{3}$ Clinical Research, University of Texas Medical Branch at Galveston, Galveston TX, USA; ${ }^{4}$ Pediatrics, Soroka University Medical Center, BeerShiva, Israel; ${ }^{5}$ Infectious Diseases/Vaccine Clinical Research, Merck Sharp \& Dohme, North Wales PA, USA; ${ }^{6}$ Clinical Biostatistics BARDS, Merck Sharp \& Dohme, North Wales PA, USA; ${ }^{7}$ Scientific Affairs, Merck Sharp \& Dohme, North Wales PA, USA; ${ }^{8}$ Regulatory Affairs, Merck Sharp \& Dohme, North Wales PA, USA; ${ }^{9}$ Infectious Diseases/Vaccine Clinical Research, Merck Sharp \& Dohme Corp., North Wales PA, USA

Background and Aims: A study to compare safety and immunogenicity profiles of PCV15 $(1,3,4,5,6 \mathrm{~A}, 6 \mathrm{~B}, 7 \mathrm{~F}, 9 \mathrm{~V}$, $14,18 \mathrm{C}, 19 \mathrm{~F}, 19 \mathrm{~A}, 22 \mathrm{~F}^{*}, 23 \mathrm{~F}, 33 \mathrm{~F}^{*}$ ) to PCV13 in pneumococcal naive healthy adults $\geq 50$ years of age. [*Non-shared serotypes with PCV13].

Methods: Study subjects ( $n=230 /$ group) received a single dose of either PCV15 or PCV13 and were followed for safety for 14 days postvaccination. Serotype-specific IgG geometric mean concentrations (GMCs) and opsnophagocytic activity (OPA) geometric mean titers (GMTs) were measured prior and 1 month postvaccination. Results: Safety profiles were comparable between adult recipients of PCV15 and PCV13. PCV15 was non-inferior to PCV13 for all 13 common serotypes, based on the serotype-specific (adjusted for baseline) IgG GMCs and OPA GMTs measured at one month postvaccination. Two-fold and 3-fold margins were used for the non-inferiority comparisons using IgG GMCs and OPA GMTs, respectively. Recipients of PCV15 had higher IgG and OPA antibodies to serotypes $22 \mathrm{~F}$ and $33 \mathrm{~F}$ than recipients of PCV13.
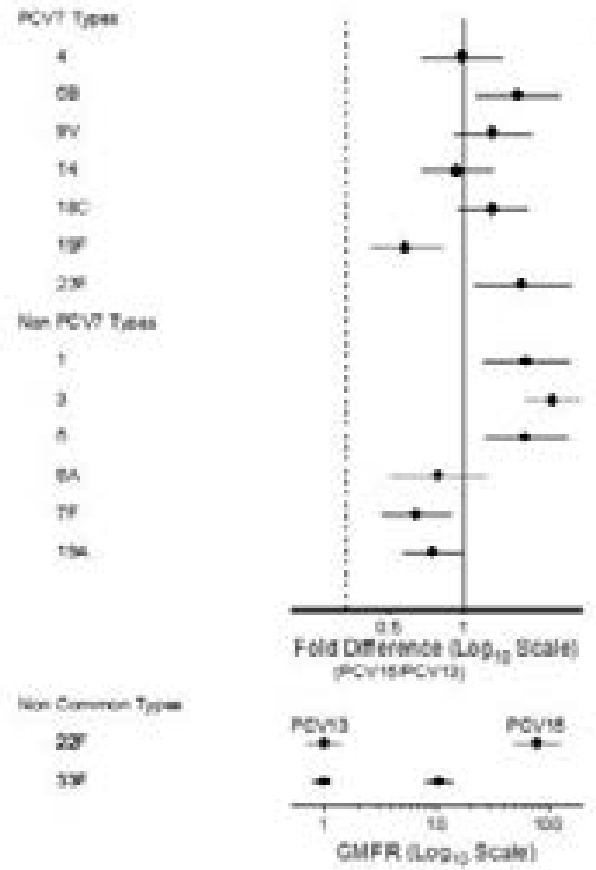

Conclusion: PCV-15 displayed an acceptable safety profile and induced serotype-specific IgG and OPA to all 15 serotypes included in the vaccine, at levels comparable to PCV-13 for the serotypes in common between the two vaccines.

Conflict of interest 
ISPPD-0541

Next Generation Vaccines

\title{
COMMUNITY ACQUIRED PNEUMONIA IMMUNISATION TRIAL IN ADULTS (CAPITA)
}

\author{
M. Bonten ${ }^{1}$, M. Bolkenbaas ${ }^{1}$, S. Huijts ${ }^{1}$, C. Webber ${ }^{2}$, S. Gault ${ }^{2}$, W. Gruber ${ }^{2}$, D. Grobbee ${ }^{1}$ \\ ${ }^{1}$ Julius Center for Health Sciences and Primary Care, UMC Utrecht, Utrecht, Netherlands; ${ }^{2}$ Vaccine Research, Pfizer, Pearl River, USA
}

Pneumococcal disease, including pneumonia, is a global public health problem, and older people are at greater risk, particularly for severe disease and complications. Conjugate vaccines have shown efficacy against invasive pneumococcal disease (IPD), pneumonia and otitis media in children, but have not been evaluated for efficacy in healthy adults. The CAPiTA study was designed to demonstrate efficacy of 13-valent pneumococcal conjugate vaccine $(13 \mathrm{VPnC})$ in prevention of a first episode of vaccine-type pneumococcal community-acquired pneumonia (CAP) (primary objective). The secondary objectives were to demonstrate efficacy in prevention of a first episode of nonbacteremic/noninvasive vaccine-type pneumococcal CAP and of vaccine-type invasive IPD. This was a randomized, double-blind clinical trial in over 84,000 participants 65 years of age and older in the Netherlands. Key eligibility criteria were no previous pneumococcal vaccination and immune competence. Participants were randomized 1:1 to receive $13 \mathrm{vPnC}$ or placebo. They were enrolled at community-based sites and home visits, and surveillance for CAP and IPD was conducted at hospitals in the areas of enrollment. Isolation of vaccine-type pneumococcus from blood or other sterile sites and a serotype-specific urinary antigen detection assay was used to identify episodes of vaccine-type CAP. Safety was also evaluated. The study started in September 2008, and reached the protocol defined 130 case accrual numbers of first episode of vaccine-type CAP at the end of August 2013. The design and primary and secondary endpoints of this study will be presented. At the time abstract submission, the data were not yet available.

Funding: Pfizer, Inc.; ClinicalTrials.gov number NCT00744263

Conflict of interest

\author{
Oral Poster Abstracts
}

\author{
ISPPD-0404 \\ Next Generation Pneumococcal Vaccines
}

\section{POPULATION VARIABILITY OF THE IMMUNE RESPONSE FOLLOWING PRIMARY VACCINATION WITH THE 10-VALENT PNEUMOCOCCAL NON-TYPEABLE HAEMOPHILUS INFLUENZAE PROTEIN D-CONJUGATE VACCINE (PHID-CV)}

\author{
D. Borys ${ }^{1}$, T. Vesikari ${ }^{2}$, M.W. Tregnaghi ${ }^{3}$, X. Sáez-Llorens ${ }^{4}$, S. Iwata ${ }^{5}$, P. Lommel ${ }^{1}$, M. Moreira ${ }^{1}$, J. Ruiz Guiñazú ${ }^{1}$ \\ ${ }^{1}$ Vaccine Discovery and Development, GlaxoSmithKline Vaccines, Wavre, Belgium; ${ }^{2}$ Vaccine Research Center, University of Tampere Medi- \\ cal School, Tampere, Finland; ${ }^{3}$ CEDEPAP, Centro de Desarrollo de Proyectos Avanzados en Pediatría, Córdoba, Argentina; ${ }^{4}$ Department of Infec- \\ tious Diseases, Hospital del Niño, Panama City, Panama; ${ }^{5}$ Department of Infectious Diseases, School of Medicine Keio University, Shinjuku-ku To- \\ kyo, Japan
}

Background and Aims: Variability in antibody responses across different geographic regions has been observed following immunization with pneumococcal conjugate vaccines. However, high efficacy against vaccine-type invasive pneumococcal disease (IPD) has been proven in different populations. We evaluated geographic variability in immune responses to PHiD-CV (GlaxoSmithKline Vaccines).

Methods: Immune responses measured by pneumococcal serotype-specific ELISA and opsonophagocytic activity (OPA) assays, one month after 3-dose primary vaccination with PHiD-CV, were assessed in several randomized controlled trials conducted across different geographic regions.

Results: PHiD-CV was immunogenic for each of the 10 pneumococcal vaccine serotypes in all trials. Biological functionality of the induced antibodies was seen in all regions. For the majority of serotypes, antibody geometric mean concentrations (GMCs) were higher in Asian and Latin American countries compared to European ones (Table). For some serotypes (i.e. 1, 4, 5), antibody GMCs were higher in Asian studies than in some of the Latin American studies. Differences in geometric mean OPA titers (GMTs) between regions appeared less pronounced for some serotypes (e.g. 4, 18C, 19F). Antibody GMCs and OPA GMTs were highest in Japan for almost all serotypes. Conclusions: Population variability in pneumococcal antibody responses measured by ELISA and in functional OPA responses was observed after PHiD-CV infant primary vaccination. Despite these differences in immune responses across regions, PHiD-CV showed similar efficacy/effectiveness against vaccine-type IPD (100\%) in Europe (Finland) ${ }^{1}$ and Latin America (Argentina, Panama, Colombia). ${ }^{2}$

${ }^{1}$ Palmu LANCET 2013

${ }^{2}$ Tregnaghi ISAAR 2013

Funding: GlaxoSmithKline Biologicals SA 


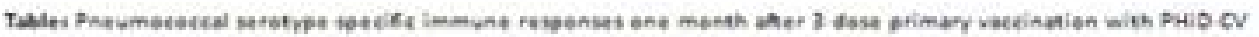

\begin{tabular}{|c|c|c|c|c|c|c|c|c|c|c|c|c|}
\hline \multirow[b]{2}{*}{$\frac{\mathrm{c}}{\mathrm{c}}$} & \multicolumn{7}{|c|}{ DuROSt } & \multicolumn{3}{|c|}{ LATS AMEgica } & \multicolumn{2}{|c|}{ Aciat } \\
\hline & 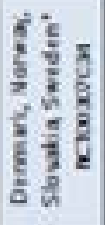 & $\begin{array}{l}\frac{y}{2} \frac{1}{2} \\
\frac{2}{2} \\
\frac{5}{8} \\
\frac{8}{8}\end{array}$ & 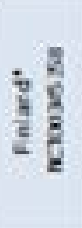 & 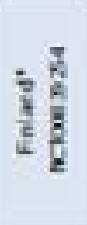 & 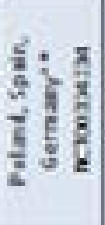 & $\frac{\pi}{2} \frac{\pi}{5}$ & $\begin{array}{l}\frac{3}{8} \\
\frac{8}{8} \\
\frac{6}{4} \\
\frac{4}{4}\end{array}$ & $\frac{z}{8} \frac{2}{8}$ & $\frac{1}{6} \frac{\pi}{8} \frac{8}{8}$ & 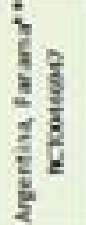 & $\begin{array}{l}\frac{2}{2} \\
\frac{n}{2} \\
\frac{5}{2} \\
\frac{2}{2}\end{array}$ & $\therefore \frac{8}{8}$ \\
\hline \multicolumn{13}{|c|}{ 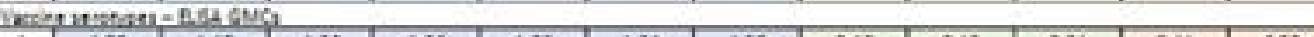 } \\
\hline+ & 134 & 125 & +30 & 726 & 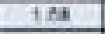 & 124 & 115 & 245 & 297 & 351 & W.1! & 469 \\
\hline+ & 173 & 213 & 194 & $2+9$ & 193. & 194 & 2.28 & 3.63 & 204 & 3.35 & 400 & 134 \\
\hline 3 & $2 \mathrm{as}$ & 204 & 2.54 & $2 \pi$ & 2.34 & int & 232 & $3 a$ & 2.24 & 420 & 432 & 134 \\
\hline 18 & 931 & 9.49 & $9 \pi$ & का: & 09 & 071 & III & (3) & 53 & 134 & 149 & 37 \\
\hline$\pi$ & $2 \%$ & 276 & 263 & $2 \%$ & $2 \%$ & 227 & 267 & 49 & 172 & 391 & 401 & 111 \\
\hline $3 y$ & 30 & 2.1 & 113 & 231 & 189 & 191. & 2.44 & 2.85 & 171 & 1.19 & 393 & 142 \\
\hline$t i$ & 259 & 969 & Im & 500 & 102 & 3it & $9 \pi$ & 481 & 972 & 4as & 9.4 & thes \\
\hline ant & 142 & 2.15 & 2.11 & WI: & 29 & 194 & 123 & 63 & CAB & 1.12 & 139 & 2632 \\
\hline ist & 203 & 350 & $24:$ & $3 x:$ & 245 & $39 t$ & 459 & 2872 & 240 & 233 & $74:$ & ard \\
\hline 23 & 0.52 & 0.72 & 0.2 & 0.58 & 214 & IAt & 294 & 27 & 200 & 13 & in & $2+1$ \\
\hline \multicolumn{13}{|c|}{ 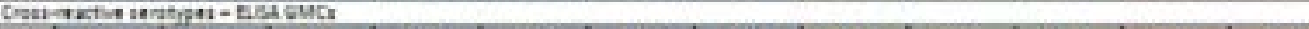 } \\
\hline 24 & 625 & 612 & 070 & 611 & OII & OA7 & 625 & 022 & 621 & 032 & 639 & $6 x:$ \\
\hline 204 & $0+1$ & ots & $d s$ & 615 & 232 & 020 & 634 & des & 024 & 029 & 020 & 0.21 \\
\hline \multicolumn{13}{|c|}{ 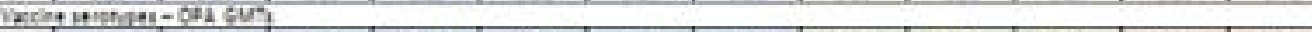 } \\
\hline 1 & 218 & 237 & 173 & 122 & 204 & 148 & 19.3 & 202 & 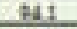 & 1929 & 1ens & 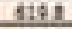 \\
\hline 4 & 208 & 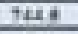 & 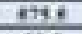 & ous & 240 & 0018 & 0.05 & 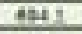 & 60 & 2910 & avia & $\operatorname{tans}$ \\
\hline 5 & 44 & $\pi 5$ & 270 & an & $\pi 3$ & Gf: & 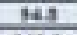 & 245 & 2429 & 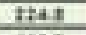 & 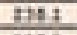 & 323 \\
\hline 39 & $2 m e$ & 2409 & $\cos \theta$ & 2029 & Q42) & xase & 2002 & 2015 & 240 & (25) & 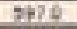 & intos \\
\hline$\pi$ & inds & 645 & 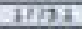 & 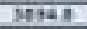 & काम & DWW:A & कित & $m$ mon & 20334 & $402 x$ & 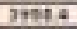 & mon \\
\hline Fy & Bथा & 12903 & 7213 & 27618 & 1075 & 1787 & 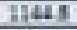 & 1969 & 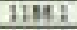 & 10724 & ES: 4 & 25054 \\
\hline 84 & 12253 & म2018 & 19233 & 1513 & 9819 & 869 & Qut & 8019 & 1291 & 9695 & 52413 & 1924 \\
\hline IK & 2111 & 2022 & ing & 2413 & 1327 & 1743 & 240 & 3049 & 2220 & $\operatorname{me}$ & 149 & $\operatorname{lng} 2$ \\
\hline $28 \%$ & 1217 & 9899 & 2847 & CAaA & 1809 & 3171 & 2027 & 2919 & $\$ 1902$ & 2110 & 2978 & 12841 \\
\hline 290 & 12757 & 20493 & 9298 & 10007 & 10498 & $970 \%$ & 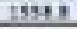 & 28113 & 21949 & 21094 & 2407 & 29178 \\
\hline \multicolumn{13}{|c|}{ 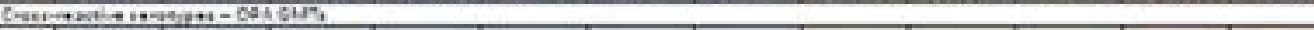 } \\
\hline $1+$ & 410 & 114 & 144 & ma & 1235 & 005 & 295 & 1593 & 1592 & 1589 & ans & 3301 \\
\hline ath & 31 & 73 & 32 & 232 & 17 & 104 & 70 & 19 & 121 & 182 & 209 & 243 \\
\hline
\end{tabular}

Conflict of interest

ISPPD-0146

Next Generation Pneumococcal Vaccines

\section{FUNCTIONAL ANTIBODY RESPONSES AFTER 2+1 OR 3+1 INFANT VACCINATION WITH 10-VALENT PNEUMOCOCCAL NON-TYPEABLE HAEMOPHILUS INFLUENZAE PROTEIN D CONJUGATE VACCINE (PHID-CV)}

T. Vesikari ${ }^{1}$, A. Forstén ${ }^{1}$, I. Seppä ${ }^{1}$, T. Puumalainen ${ }^{2}$, A. Soininen ${ }^{2}$, M. Traskine ${ }^{3}$, M. Hezareh ${ }^{3}$, M. Moreira ${ }^{3}$, D. Borys ${ }^{3}$, L. Schuerman ${ }^{3}$

${ }^{1}$ Vaccine Research Center, University of Tampere Medical School, Tampere, Finland; ${ }^{2}$ Medical Department, GlaxoSmithKline, Espoo, Finland

${ }^{3}$ Vaccine Discovery and Development, GlaxoSmithKline Vaccines, Wavre, Belgium

Background and Aims: The PHiD-CV (GlaxoSmithKline Vaccines) Finnish invasive pneumococcal disease (IPD) effectiveness study (FinIP, NCT00861380) demonstrated $100 \%$ and $92 \%$ vaccine effectiveness against vaccinetype IPD for 3+1 and 2+1 infant schedules, respectively. Reduction of all acute otitis media episodes and vaccinetype nasopharyngeal carriage were also observed in study 053 (NCT00839254) nested in FinIP. In addition to immunogenicity measured by ELISA (previously presented), here we assessed functional opsonophagocytic activity (OPA) to better characterize the immune response.

Methods: Healthy infants $(n=5093)$ enrolled between 6 weeks and 6 months of age $(M)$, received either PHiD-CV or a control vaccine (hepatitis B) at $3,4,5,11-12 \mathrm{M}(3+1)$ or $3,5,11-12 \mathrm{M}(2+1)$. OPA responses were assessed in a subset of participants $(n=705)$ post-primary and post-booster vaccination.

Results: For most vaccine serotypes OPA responses tended to be higher after 3-dose than after 2-dose primary vaccination (Table). These differences were less pronounced after booster vaccination. After booster vaccination at $11-12 \mathrm{M}$, for each vaccine serotype with both schedules, $\geq 94.0 \%$ participants had OPA titers $\geq 8$, except for serotype 1 with the $2+1$ schedule (86.5\%).

Conclusions: PHiD-CV administered according to $2+1$ or $3+1$ infant schedules elicited functional OPA responses, with a tendency for higher responses with a $3+1$ schedule, especially post-primary vaccination.

Funding: GlaxoSmithKline Biologicals SA 
TAMU

Post-primary and post-booster serotype-specific neometric mean OPA titen [according to-protocol cohort for immunogenicity]

\begin{tabular}{|c|c|c|c|c|c|c|c|}
\hline & \multicolumn{4}{|c|}{$3+1$ uhedule } & \multicolumn{3}{|c|}{$2+1$ vhedule } \\
\hline & \multicolumn{2}{|c|}{ PHID CV group } & \multicolumn{2}{|c|}{ Control enoup } & \multicolumn{2}{|c|}{ PHiD CV grous } & \multirow{2}{*}{ 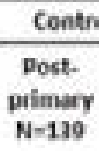 } \\
\hline & $\begin{array}{l}\text { Dost- } \\
\text { erimary } \\
N=202\end{array}$ & $\begin{array}{l}\text { Dost- } \\
\text { boonter } \\
\text { N-1sS }\end{array}$ & $\begin{array}{l}\text { Post- } \\
\text { Dintary } \\
N \rightarrow 118\end{array}$ & $\begin{array}{l}\text { Dost- } \\
\text { boustei } \\
\text { N-120 }\end{array}$ & $\begin{array}{l}\text { Post- } \\
\text { primary } \\
N=106\end{array}$ & $\begin{array}{l}\text { Post- } \\
\text { boostes } \\
\text { N-193 }\end{array}$ & \\
\hline Serobype & & \multicolumn{6}{|c|}{ Vaccine serotypes } \\
\hline 1 & 52.8 & 300.6 & 4.1 & 4.6 & 38.3 & 2509 & 4.1 \\
\hline 4 & 245.6 & 1705.7 & 4.6 & 5.1 & 552.0 & 1143.4 & 4.8 \\
\hline 5 & as. 9 & 191.6 & 4.9 & 4.1. & $4 a s$ & 1456 & 40 \\
\hline 68 & 740.5 & 736.3 & 4.4 & 6.1 & 258.6 & 8791 & 4.2 \\
\hline w & 3594,8 & $\sin 90$ & 87.6 & 4367 & 2553.5 & 4863.2 & 59.6 \\
\hline FV & 2729.0 & 3492.2 & 6.5 & 24.7 & 1687.2 & $31 \% 8.0$ & 5.3 \\
\hline 14 & 1831.3 & 26572 & 10.5 & 141 & 1146.3 & 1724.2 & 7.3 \\
\hline $18 C$ & 5.3 .3 & 1665.1 & 4.9 & 4.0 & 230.6 & 1052.2 & 4.0 \\
\hline 194 & 649.6 & 1025.0 & 40 & 4,4 & 193.6 & 154.6 & 4.1 \\
\hline \multirow[t]{2}{*}{$23 r$} & 1300.7 & 3245.2 & 7.0 & 24.8 & $\cos 7.1$ & 2630.7 & 5.6 \\
\hline & & \multicolumn{6}{|c|}{ Cross-reactive seretypes } \\
\hline GA & $90 . \mathrm{a}$ & 173.8 & 4.1 & 5.3 & 43.1 & 2859 & 4.4 \\
\hline $13 \mathrm{~h}$ & 25.2 & 145.9 & 4.3 & 4.3 & 11.9 & 78.9 & 4.1 \\
\hline
\end{tabular}

Percentages of children with opA titers 23 (accouding; to-protocol cohort for immanopenldity)

\begin{tabular}{|c|c|c|c|c|c|c|c|}
\hline & \multicolumn{4}{|c|}{ 3.1 sehedule } & \multicolumn{3}{|c|}{$2+1$ vehedule } \\
\hline & \multicolumn{2}{|c|}{ PHID CV group } & \multicolumn{2}{|c|}{ Control group } & \multicolumn{2}{|c|}{ PHID CV group } & \multirow{2}{*}{$\begin{array}{c}\text { Contr } \\
\text { Pust- } \\
\text { primary } \\
n=139\end{array}$} \\
\hline & $\begin{array}{l}\text { Prent } \\
\text { pelmary } \\
N=202\end{array}$ & $\begin{array}{l}\text { Post. } \\
\text { booster } \\
\text { huses }\end{array}$ & $\begin{array}{l}\text { Post- } \\
\text { pdimary } \\
\text { Nons.18 }\end{array}$ & $\begin{array}{c}\text { Pront - } \\
\text { booster } \\
N=120\end{array}$ & $\begin{array}{l}\text { Pust. } \\
\text { primary } \\
\text { numiso }\end{array}$ & $\begin{array}{l}\text { Post- } \\
\text { booster } \\
N=18 y\end{array}$ & \\
\hline serofype & & \multicolumn{6}{|c|}{ vaccine serofypes } \\
\hline 1 & 71.9 & 94,0 & a.d & 5.8 & $\cos 8$ & 80.5 & 0.7 \\
\hline 4 & 100 & 100 & 27 & 7.0 & 99.5 & 995 & 3.7 \\
\hline 5 & 930 & 96.8 & 0.8 & $0 . t$ & 88.2 & 9.2 & 0.0 \\
\hline 68 & 897 & 94.5 & 1.1 & 6.8 & 10.1 & 96.2 & 0.8 \\
\hline$\pi$ & 100 & 100 & 08.9 & 34.0 & 99.9 & 100 & 99.3 \\
\hline $9 v$ & 100 & 100 & 12.5 & $4 \$ 9$ & 108 & 100 & 7,7 \\
\hline 14 & 995 & 100 & 20.5 & 25.6 & 98.4 & 100 & 14.5 \\
\hline $18 \mathrm{C}$ & 97.9 & 58.9 & 0.6 & 0.0 & 91.2 & 160 & 0.0 \\
\hline $19 f$ & 97.4 & 96.7 & 0.0 & 2.5 & 87.2 & 96.8 & 1.4 \\
\hline \multirow[t]{2}{*}{$23 \mathrm{~F}$} & 929 & 99.5 & 8.: & 261 & 89.4 & 97.3 & 6.1 \\
\hline & & \multicolumn{6}{|c|}{ Crose-reactive serotypes } \\
\hline 6A & 72.7 & 70.0 & 0.9 & 6.1 & 56.8 & bs. & 1.5 \\
\hline $19 \mathrm{~A}$ & 4.25 & I8.3 & 23 & 3.4 & $28 y$ & 69.4 & 1.5 \\
\hline
\end{tabular}

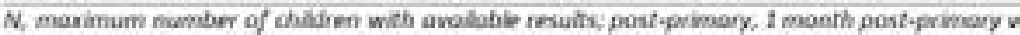

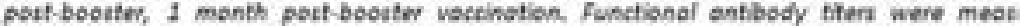

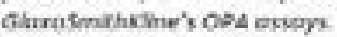

Conflict of interest

ISPPD-0122

Next Generation Pneumococcal Vaccines

\section{IMMUNE SERA FROM ADULTS IMMUNIZED WITH KILLED WHOLE CELL NONENCAPSULATED VACCINE PROTECTS MICE FROM FATAL INFECTION WITH TYPE 3 PNEUMOCOCCI}

D. Briles ${ }^{1}$, J. King ${ }^{1}$, Y. Hale ${ }^{1}$, R. Malley², P. Anderson², C. Keech ${ }^{3}$, A. Tate ${ }^{3}$, J. Maisonneuve ${ }^{3}$, M. Alderson ${ }^{3}$

${ }^{1}$ Microbiology, University of Alabama at Birmingham, Birmingham, USA; ${ }^{2}$ Division of Infectious Diseases, Department of Pediatrics, Boston Childrens Hospital, Boston, USA; ${ }^{3}$ Vaccine Development, Path, Seattle, USA

The purpose of this study was to evaluate the ability of the killed whole cell vaccine adsorbed to alum (wSP) being developed by PATH and Boston Children's Hospital to elicit antibody in adults that is protective against otherwise fatal sepsis in mice infected i.v. with virulent type 3, A66.1, Streptococcus pneumoniae. Of 14 volunteers immunized in a Phase 1 trial with 300 or $600 \mu \mathrm{g}$ of wSP, 8 showed statistically significant (Mann-Whitney) protection based on hours to moribund by their post-immune, compared to their pre-immune sera, resulting in mice that lived $>48 \mathrm{~h}$ (median) longer than those given pre-immune sera. Of the 9 pre- and post-immune pairs from the placebo immunizations only one pair showed a statistically significant change in protection, with a $>48 \mathrm{~h}$ extension of life. The observation of 8 protective sera from 14 immunized volunteers was statistically different by the Fisher Exact test from 1 of 9 of the placebo controls $(p=0.0397)$. The immunity to $S$. pneumoniae in the single placebo volunteer might have been due to natural exposure of the volunteer to pneumococci or some other microbe with a cross-reacting antigens. As compared to the pre-immune sera, post-immune sera from three of the immunized volunteers, but none of the placebo volunteers, mediated a significantly higher fraction of mice to be protected against becoming moribund during the 14 days the infected mice were monitored. Together these results provide strong support for continued development of wSP as a potential human vaccine. 
ISPPD-0327

Next Generation Pneumococcal Vaccines

TH17 RESPONSES TO PNEUMOCOCCAL PROTEIN ANTIGENS IN CHILDREN'S NASAL ASSOCIATED LYMPHOID TISSUE OBTAINED AT ADENOIDECTOMY COULD GUIDE VACCINE FORMULATIONS

\author{
A. Finn ${ }^{1}$, E. Oliver ${ }^{1}$, C. Pope ${ }^{1}$, A.D. Ogunniyi ${ }^{2}$, T.J. Mitchell ${ }^{3}$, M. Skoberne ${ }^{4}$, J. Flechtner ${ }^{4}$, R. Malley ${ }^{5}$ \\ ${ }^{1}$ Cellular and Molecular Medicine, University of Bristol, Bristol, United Kingdom; ${ }^{2}$ Research Centre for Infectious Diseases Molecular \& Biomedi- \\ cal Science, University of Adelaide, Adelaide, Australia; ${ }^{3}$ Immunity \& Infection, University of Birmingham, Birmingham, United Kingdom; ${ }^{4}$ Incor- \\ porated, Genocea Biosciences, Boston, USA; ${ }^{5}$ Harvard Medical School, Boston Childrens Hospital, Boston, USA
}

Background and Aims: Protein antigens are sought as adjuncts or alternatives to pneumococcal capsular polysaccharide/conjugate vaccines. Current vaccines have important effects on pneumococcal transmission. Protein vaccines may also exert such effects and may do so via TH17 mediated pathways, as described in murine models. Methods: We obtained adenoidal tissue, blood and nasal swabs from surgical patients at Bristol Children's Hospital, with informed consent. Mononuclear cell cultures were stimulated with recombinant proteins and supernatants assayed for IL17 (day7) and IL22 (day11) by immunoassay. Phenotype of cytokine producing cells (day7) was detected using standard flow cytometric techniques. Differences described were statistically significant $p<0.05$. Results: In general cytokine production by blood cells exceeded that by adenoidal cells. Whereas median IL17 \& IL22 production in blood was similar to or higher than that induced by whole cell antigen (positive control) for $5 / 7$ proteins, in adenoids this was only true for two (Choline binding protein A and SP1912). Among 3 novel T-cell response-inducing proteins, SP1912 was consistently the best stimulator of IL17 \& IL22 responses. No consistent differences in cytokine production between swab pneumococcal culture positive and negative children were seen.

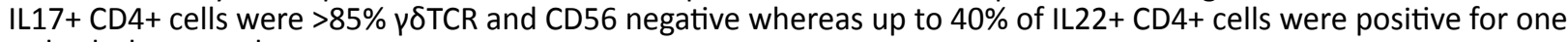
or both these markers.

Conclusion: Pneumococcal protein induction of IL17 and IL22 by lymphocytes may relate to immune responses which reduce colonisation and thus transmission. However IL22 may also be produced significantly by cells with a more "innate" phenotype.

Acknowledgement: This study was supported by PATH

Conflict of interest

ISPPD-0178

Next Generation Pneumococcal Vaccines

\title{
DESIGN AND EVALUATION OF A 12-VALENT PNEUMOCOCCAL VACCINE USING THE MULTIPLE ANTIGEN PRESENTING SYSTEM (MAPS)
}

F. Zhang ${ }^{1}$, Y.J. Lu' ${ }^{1}$, M. Herd ${ }^{1}$, R. Malley ${ }^{1}$

${ }^{1}$ Infectious Diseases, Boston Children's Hospital, Boston, USA

Background and Aims: Protection against pneumococcal disease involves multiple immune mechanisms. We recently published our novel vaccine platform, MAPS, which generates macromolecular complexes of polysaccharides (PS) and proteins via highly specific and efficient affinity coupling (Figure 1). Mice and rabbits immunized with MAPS vaccines develop B- and T-cell responses specific to the antigens. Here we tested this technology by developing a multivalent pneumococcal MAPS vaccine.

Methods: Twelve MAPS complexes were made using pneumococcal PS (all PCV13 serotypes except type 3), each of which was coupled with one of four pneumococcal proteins (each protein carrier was used for 3 serotypes). Mice were immunized with either the 12-valent MAPS with aluminum or the commercially available PCV13. Anti-PS antibodies, B- and Th17-responses to the protein carriers were analyzed after two immunizations.

Results: For most serotypes, immunization with MAPS vaccine induced similar levels of anti-PS antibodies as generated by PCV13, except for type14 for which MAPS was clearly superior (Figure 2). For serotypes 19A and $19 F$, MAPS responses were slightly lower than with PCV13, but increasing the concentration of these serotypes in the MAPS vaccine improved the response. Mice that received MAPS vaccine also developed antibody and Th17 responses against all four pneumococcal carrier proteins.

Conclusion: We demonstrate here that a multivalent pneumococcal MAPS vaccine generated multipronged B-and T-cell immune responses. Such a MAPS-based vaccine may offer significant advantages towards conferring serotypedependent and -independent immunity to pneumococcus.

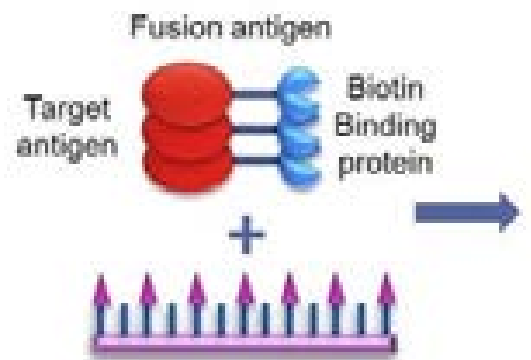

Biotinylated PS

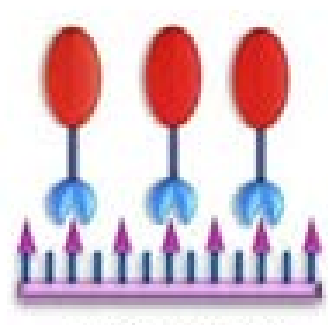

MAPS complex 


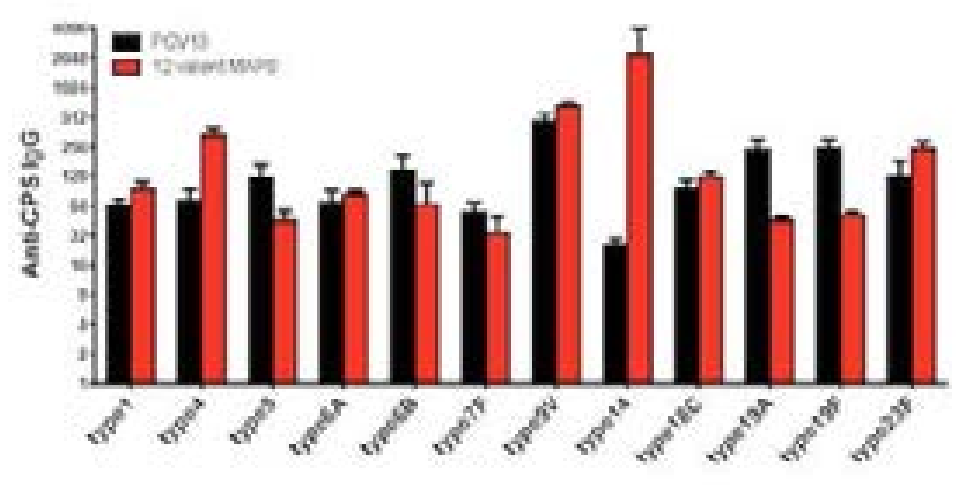

No conflict of interest

ISPPD-0197

Next Generation Pneumococcal Vaccines

\section{SAFETY AND IMMUNOGENICITY OF 15-VALENT PNEUMOCOCCAL CONJUGATE VACCINE (PCV-15) COMPARED TO PCV-13 IN HEALTHY INFANTS}

D. Greenberg ${ }^{1}$, T. Vesikari ${ }^{2}$, C. Peltier ${ }^{3}$, D.C. Hurley ${ }^{4}$, P.A. Hoover ${ }^{5}$, R.D. McFetridge ${ }^{6}$, M. Dallas ${ }^{6}$, J. Hartzel ${ }^{6}$, R.D. Marchese $^{6}$, J.E. Stek ${ }^{7}$, C. Abeygunardawana ${ }^{8}$, D. Isaacman ${ }^{6}$, L. Musey ${ }^{6}$

${ }^{1}$ Pediatrics, Soroka University Medical Center, Beer-Shiva, Israel; ${ }^{2}$ Pediatrics, University of Tampere, Tampere, Finland; ${ }^{3}$ Pediatrics, Pediatric Associates of Mont Carmel, Cincinnati OH, USA; ${ }^{4}$ Pediatrics, Cottonwood Pediatrics, Murray UT, USA; ${ }^{5}$ Infectious Diseases/Vaccine Clinical Research, Merck Sharp \& Dohme, North Wales PA, USA; ${ }^{6}$ Infectious Diseases/Vaccine Clinical Research, Merck Sharp \& Dohme Corp., North Wales PA, USA; ${ }^{7}$ Scientific Affairs, Merck Sharp \& Dohme Corp., North Wales PA, USA; ${ }^{8}$ Regulatory Affairs, Merck Sharp \& Dohme Corp., North Wales PA, USA

Background and Aims: A study to compare safety and immunogenicity of PCV15 $(1,3,4,5,6 \mathrm{~A}, 6 \mathrm{~B}, 7 \mathrm{~F}, 9 \mathrm{~V}, 14,18 \mathrm{C}$, $19 \mathrm{~F}, 19 \mathrm{~A}, 22 \mathrm{~F}^{*}, 23 \mathrm{~F}, 33 \mathrm{~F}^{*}$ ) to PCV13 in infants.

Methods: Vaccines were administered concomitantly with other pediatric vaccines at 2, 4, 6, and 12-15 months of age. Subjects received either aluminum adjuvanted PCV-15 [n=378], non-adjuvanted PCV-15 [n=386], or PCV13 [n=378]. Safety profiles were compared after each dose. Serotype-specific IgG geometric mean concentrations (GMCs) and opsnophagocytic activity (OPA) to PCV-15 were compared to PCV-13 for shared serotypes at postdose (PD) 3 and PD4.

Results: Most subjects in each group reported clinical adverse events (AE). Comparable proportion of subjects reported serious AEs across groups (adjuvanted PCV-15: 6.8\%; non-adjuvanted PCV-15: 7.1\%; PCV-13: 7.7\%). At PD3, PCV-15 met non-inferiority criteria for 10 of 13 shared serotypes with PCV-13, but failed to meet the criteria for serotypes 6A, 6B, and 19A. Serotype-specific GMCs PD3 were generally lower for both PCV-15 formulations than PCV-13, except for serotype 3. Both formulations of PCV-15 induced higher GMCs and OPA than PCV-13 to serotypes $22 \mathrm{~F}$ and 33F.Compared to PD3, differences in antibody responses between both formulations of PCV-15 and PCV-13 were generally less pronounced at PD4; only 6A and 19A did not meet non-inferiority criteria at PD4 based on GMC comparisons.

Conclusion: Both formulations of PCV-15 displayed acceptable safety profiles and induced serotype-specific IgG and OPA to all 15 serotypes included in the vaccine. IgG GMCs were generally lower in recipients of PCV-15 than PCV-13. *Non-shared serotypes

Conflict of interest

ISPPD-0407

Next Generation Pneumococcal Vaccines

\section{REACTOGENICITY, SAFETY AND IMMUNOGENICITY OF A PROTEIN-BASED PNEUMOCOCCAL VACCINE IN GAMBIAN CHILDREN AGED 2-4 YEARS: PHASE II RANDOMIZED STUDY}

A. Odutola ${ }^{1}$, M.O. Ota ${ }^{1}$, M. Antonio ${ }^{1}$, O.E. Ogundare ${ }^{1}$, P. Owiafe ${ }^{1}$, A. Worwui ${ }^{1}$, B. Greenwood ${ }^{2}$, M. Alderson ${ }^{3}$, M. Traskine ${ }^{4}$, K. Dobbelaere ${ }^{4}$, D. Borys ${ }^{4}$

${ }^{1}$ Vaccinology Theme, Medical Research Council Unit The Gambia, Fajara, Gambia; ${ }^{2}$ Faculty of Infectious and Tropical Diseases, London School of Hygiene \& Tropical Medicine, London, United Kingdom; ${ }^{3}$ Program for Appropriate Technology in Health, Seattle, USA ${ }^{4}$ GlaxoSmithKline Vaccines, Wavre, Belgium

Background and Aims: The safety, reactogenicity and immunogenicity of an investigational vaccine (PHiD-CV/dPly/

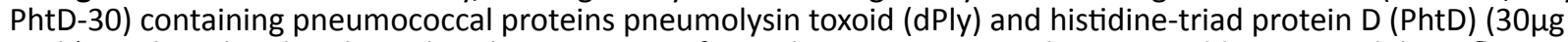
each) combined with polysaccharide conjugates of 10-valent pneumococcal non-typeable Haemophilus influenzae protein D conjugate vaccine (PHiD-CV) were evaluated in children in The Gambia.

Methods: In this phase II, observer-blinded study (NCT01262872), 120 children aged 2-4 years, not previously vaccinated against Streptococcus pneumoniae, were randomized (1:1) to receive 1 dose of PHiD-CV/dPly/PhtD-30 
or 13-valent pneumococcal $\mathrm{CRM}_{197}$-conjugated vaccine (13vCRM). Solicited/unsolicited adverse events (AEs) within 4/31 days, respectively, and serious AEs (SAEs) within 6 months post-vaccination were recorded. Hematological, biochemical and serological assessments were performed pre-vaccination and 1 month post-vaccination.

Results: No significant difference between groups in the incidence of grade 3 vaccine-related AEs or SAEs was observed; grade 3 swelling was reported for 1 PHiD-CV/dPly/PhtD-30 recipient; unsolicited AEs for 21.7\% PHiD$\mathrm{CV} / \mathrm{dPly} / \mathrm{PhtD}-30$ and $11.7 \% 13 \mathrm{vCRM}$ recipients. No clinically significant changes in hematological/biochemical parameters were observed. Post-vaccination, for each vaccine-serotype, $\geq 96.2 \%$ of PHiD-CV/dPly/PhtD-30 recipients had polysaccharide antibody concentrations $\geq 0.2 \mu \mathrm{g} / \mathrm{mL}$, except for serotypes $6 \mathrm{~B}$ and $23 \mathrm{~F} ; \geq 94.1 \%$ had opsonophagocytic activity (OPA) titers $\geq 8$, except for serotypes 1,5 and $6 B$ (Table). Serotype-specific polysaccharide antibody concentrations, OPA titers, Ply and PhtD antibodies (Table) were higher after PHiD-CV/dPly/PhtD-30 vaccination than before.

Conclusion: PHiD-CV/dPly/PhtD-30 is well-tolerated and immunogenic in young Gambian children.

Funding: GlaxoSmithKline Biologicals SA, PATH

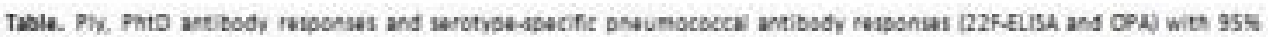

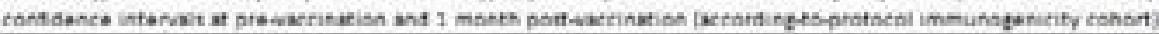

\begin{tabular}{|c|c|c|c|c|c|c|c|c|}
\hline \multirow[b]{3}{*}{$\begin{array}{c}\text { Antigen } \\
\text { nit } \\
\text { nhan }\end{array}$} & \multicolumn{4}{|c|}{ Kivivitf } & \multicolumn{4}{|c|}{ GNC $\{. W / m\}$} \\
\hline & \multicolumn{2}{|c|}{ 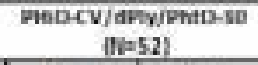 } & \multicolumn{2}{|c|}{ 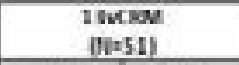 } & \multicolumn{2}{|c|}{$\begin{array}{c}\text { MeDcv/abw/phtD-wo } \\
\text { (Nns2] }\end{array}$} & \multicolumn{2}{|c|}{ 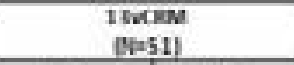 } \\
\hline & 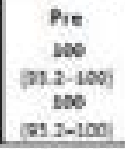 & 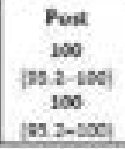 & 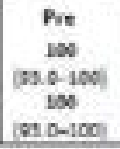 & 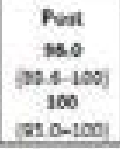 & 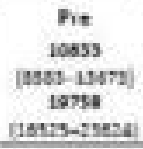 & 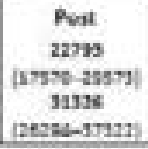 & 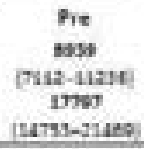 & 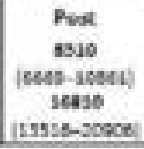 \\
\hline & \multicolumn{4}{|c|}{22 tearsh $(1020.2 \mathrm{~kg} / \mathrm{mt})$} & \multicolumn{4}{|c|}{ OPA (N2a) } \\
\hline & \multicolumn{2}{|c|}{ 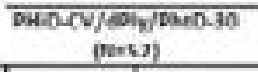 } & \multicolumn{2}{|c|}{ 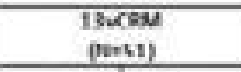 } & \multicolumn{2}{|c|}{ 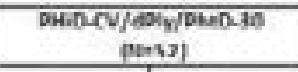 } & \multicolumn{2}{|c|}{$\begin{array}{l}\text { 13VKRM } \\
\text { (Nos1) }\end{array}$} \\
\hline Seretrie & Pis & Pont & Pre & Pest & Pee & Post & Pre & Peat \\
\hline 1 & $\frac{231}{1325-30.2}$ & $\frac{m-1}{(4)+-100)}$ & $\stackrel{3.8}{(2.2-2:-4 \mid}$ & $\stackrel{160}{0.0-106 \mid}$ & 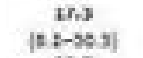 & $\begin{array}{c}319 \\
\{2+4-46 \text { de }\}\end{array}$ & as & $\operatorname{man}_{(20)-46)}$ \\
\hline 4 & $\frac{767}{(11124 \pi)}$ & $2013=1 \mathrm{~m}$ & $\begin{array}{c}x 4 \\
(x<-4)\end{array}$ & 100 & $\frac{44.7}{140.78}$ & act & $\begin{array}{l}543 \\
\mid 413 \times n) 4\}\end{array}$ & $\begin{array}{c}300 \\
\text { antos }\end{array}$ \\
\hline 3 & $\ln _{|x:-30,3|}$ & 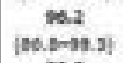 & $\underset{[3.2-21.4]}{\sin }$ & $\cos _{3-1}$ & $\stackrel{10}{|0.0-20 x|}$ & 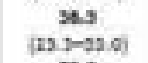 & $\cos _{(0,3)}^{20}$ & 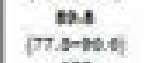 \\
\hline 60 & & $\mid 20.504$ & & & $\begin{array}{c}n=0 \\
\sin s-50\end{array}$ & 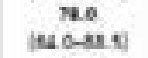 & 2120.92. & $\operatorname{les} \alpha-100$ \\
\hline$F$ & $\stackrel{123}{|+4-23,4|}$ & & $\underset{[7.4-22.9]}{20.5}$ & 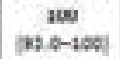 & $\ln _{100}$ & $\begin{array}{c}36 \\
(3.2-169)\end{array}$ & 200 & $\begin{array}{c}200 \\
{[020-206]}\end{array}$ \\
\hline $9 N$ & 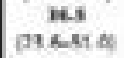 & [as.2) & $\begin{array}{c}\operatorname{nad} \\
{[24250 \mid}\end{array}$ & meo & $\operatorname{loc}_{\operatorname{los}}^{0.2}$ & {$[0 x+100$} & oses & as atos \\
\hline 24 & 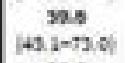 & $\frac{5.1}{(a), 700}$ & 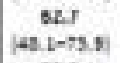 & $\ln _{0-1001}^{100}$ & $\frac{0.5}{|+2.3-7,3|}$ & 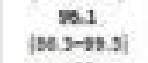 & $\frac{63.4}{(3 a .)-2 \pi}$ & 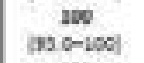 \\
\hline $18 \mathrm{C}$ & $\begin{array}{c}\text { 3es } \\
\text { (at). }\end{array}$ & 300 & $\begin{array}{c}\text { N.3. } \\
|22.4-42.6|\end{array}$ & $\begin{array}{c}100 \\
|210-196|\end{array}$ & $=0$ & $(61.200$ & $\begin{array}{c}12.5 \\
(4,9-21.3)\end{array}$ & $\begin{array}{c}306 \\
|02,-406|\end{array}$ \\
\hline 191 & $\frac{435}{(40.0-76.4}$ & $\begin{array}{c}100 \\
01.2 \times 100)\end{array}$ & ${ }_{|20.3-978|}$ & $\begin{array}{c}100 \\
|x=-100|\end{array}$ & $\underset{|14.3-20.6|}{n s}$ & $\frac{1}{\text { [se }:-20.2 \text { ] }}$ & $\begin{array}{c}12.7 \\
(7.0-28.8)\end{array}$ & 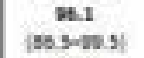 \\
\hline $23 r$ & $\begin{array}{c}34 \\
13.2-216\end{array}$ & $\begin{array}{c}\text { esit } \\
\text { (soctice) }\end{array}$ & $\begin{array}{l}\text { 13.7 } \\
\mid 5.7-36.2)\end{array}$ & mas & 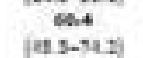 & $\begin{array}{c}\sec 1 \\
\text { [ns } 1-901\end{array}$ & $\begin{array}{l}\sec \\
\text { [3.e-es. }\end{array}$ & $\begin{array}{c}\text { ved } \\
14-400\end{array}$ \\
\hline
\end{tabular}

Conflict of interest

ISPPD-0061

Next Generation Pneumococcal Vaccines

\section{ENGINEERED NEXT GENERATION MULTIVALENT PRINT? NANOPARTICULATE PNEUMOCOCCAL VACCINES: POLYSACCHARIDE PROTEIN VACCINES STIMULATE ROBUST B AND T-CELL IMMUNE RESPONSE}

S. Rele ${ }^{1}$, A. Beletskii ${ }^{1}$, C. Bernasconi ${ }^{1}$, J. Conley ${ }^{1}$, M. Earl ${ }^{1}$, G. Fawcett ${ }^{1}$, J. Hansen ${ }^{1}$, L. Kelly ${ }^{1}$, M. Lily ${ }^{1}$, F. Malinoski $^{1}$, J. Marchand ${ }^{1}$, N. Meyer ${ }^{1}$, S. Rele ${ }^{1}$, R. Robeson ${ }^{1}$, M. Stone ${ }^{1}$, R. Yadavalli ${ }^{1}$, B. Yerxa ${ }^{1}$, J. Maisonneuve ${ }^{2}$, M. Alderson ${ }^{2}$

${ }^{1}$ Polysaccharide Protein Vaccines, LIQUIDIA TECHNOLOGIES, Durham, USA; ${ }^{2}$ Pneumococcal Vaccines, Path, Seattle, USA

Background and Aims: A nanoparticle vaccine consisting of pneumococcal polysaccharides (PnPs) and protein antigens (toxoids, surface proteins) has the potential to confer broader and enhanced protective immunity (antibody/cellular) against IPD and carriage/colonization. In partnership with PATH, Liquidia is developing a next generation multivalent nanoparticulate polysaccharide vaccine for Streptococcus pneumoniae based on ${ }^{\circledR}$ PRINT technology which can elicit antibody and cellular (IL-17) responses. For example, ${ }^{\circledR}$ PRINT nanoparticle multivalent vaccines which incorporates key capsular PnPs (1, 4, 5, 6A, 14, 19A, 23F) and pneumococcal carrier protein/ immunogen (mutant pneumolysin, PLD and pneumococcal surface protein A, PspA) has been developed.

Methods: Mice and rabbits $(n=6)$ were immunized subcutaneously or intramuscularly with defined serotype/ protein ${ }^{\circledR}$ PRINT formulations (day 1/29/57). The IgG (PnPs/protein) response to ${ }^{\circledR}$ PRINT formulations was evaluated and calibrated against Prevnar $13^{\circledR}$ using WHO IgG ELISA protocol adapted for animal models. Functional responses to animal sera were evaluated by opsonophagocytic killing (OPK) assay. Spleens collected on day 70 were analyzed for IL-17 and IFN- $\gamma$ release from splenocytes in response to antigen stimulation.

Results: Single and multivalent serotype nonadjuvanted ${ }^{\circledR}$ PRINT formulations elicited robust serotype-specific antiPnPs1, 4, 5, 6A, 14, 19A, 23F and OPK responses equivalent to Prevnar 13. ${ }^{\circledR} \mathrm{PRINT}$ formulations also induced PLD and PspA IgG antibody responses on par with soluble PLD and PspA antigens. Significantly, PLD/PnPs1, 5, $14{ }^{\circledR}$ PRINT 
particles generated IL-17 responses.

Conclusion: Formulation of S. pneumoniae protein and polysaccharide antigens in ${ }^{\circledR}$ PRINT formulations leads to antibody and cellular immune responses (Th1 and Th17). Incorporation of structurally/chemically diverse antigens demonstrates a broad potential of the ${ }^{\circledR}$ PRINT platform.

No conflict of interest

ISPPD-0283

Next Generation Pneumococcal Vaccines

\section{DIFFERENTIAL B CELL MEMORY IN CHILDREN AFTER VACCINATION WITH A 10- OR 13-VALENT PNEUMOCOCCAL CONJUGATE VACCINE}

E. van Westen ${ }^{1}$, A.J. Wijmenga ${ }^{1}$, H.H. van Dijken ${ }^{1}$, J. van Gaans ${ }^{1}$, B. Kuipers ${ }^{1}$, G.A. Berbers ${ }^{1}$, N.Y. Rots ${ }^{1}$, C.A. van Els ${ }^{1}$

${ }^{1}$ Centre for Infectious Disease Control, National Institute for Public Health and the Environment, Bilthoven, Netherlands

Background: Pneumococcal polysaccharide conjugate vaccines (PCVs) against infections with Streptococcus pneumoniae induce long-term immunological memory. Memory B cells might be a better predictor of long-term immunity compared to levels of antibodies.

In this study, levels of specific plasma- and memory B cells induced by a 10-valent PCV or a 13-valent PCV were compared.

Methods: Children were vaccinated with PCV10 or PCV13 at 2, 3, 4 and 11 months of age (Dutch NIP). Blood samples were collected before or 7-9 days after the 11 months booster dose.

Serotype specific plasma- and memory B cells were measured in PBMC against 6 serotypes by ELISpot. Specific IgG antibody levels were determined in plasma samples by multiplex immuno assay.

Results: Levels of plasma cells were, pre- and post-booster, comparable for PCV13 and PCV10, except for serotypes $6 \mathrm{~B}$ and 1 pre-booster, and the PCV13-specific serotypes post-booster.

PCV13 vaccination resulted in significantly higher numbers of memory B cells for all serotypes, before as well as after the booster dose, compared to PCV10 vaccination, except for serotype 1 post-booster.

IgG levels at 11 months of age were significantly higher for serotypes 6A, 19A and 19F, pre- as well as post-booster, in PCV13- compared to PCV10 vaccinated children, except for serotype 6B which was lower pre-booster.

Conclusion: Higher levels of memory B cells after PCV13 vaccination may predict a better long-term memory compared to PCV10. These high levels of memory B cells together with the higher IgG levels suggest a better immunogenicity of PCV13 compared to PCV10.

No conflict of interest

ISPPD-0312

Next Generation Pneumococcal Vaccines

\section{DIRECT COMPARISON OF IMMUNOGENICITY INDUCED BY A BOOSTER DOSE OF PNEUMOCOCCAL CONJUGATE VACCINES SYNFLORIX ${ }^{\circledR}$ OR PREVENAR-13 ${ }^{\circledR}$ IN INFANTS}

A.J. Wijmenga-Monsuur ${ }^{1}$, M.J. Knol ${ }^{1}$, E. van Westen ${ }^{1}$, R.M.J. Jongerius ${ }^{1}$, M. Zancolli ${ }^{2}$, D. Goldblatt ${ }^{2}$, P.G.M. van Gageldonk $^{1}$, I. Tcherniaeva ${ }^{1}$, G.A.M. Berbers ${ }^{1}$, N.Y. Rots ${ }^{1}$

${ }^{1}$ Centre for Infectious Disease Control, National Institute for Public Health and the Environment, Bilthoven, Netherlands; ${ }^{2}$ University College London, Institute of Child Health, London, United Kingdom

Background \& Aims: Pneumococcal polysaccharide conjugate vaccines (PCVs) protect against infections with Streptococcus pneumoniae. Since 2009, a 10 and 13-valent PCV are available which differ in serotype number, antigen concentration and carrier. This study compared, head-to-head, PCV10 versus PCV13 immunogenicity administered as a booster at 11-months of age.

Methods: 132 Dutch infants born August-December 2011 were vaccinated with either PCV10 (during regular well baby clinic visits) or PCV13 (during home visits) and DTaP-IPV-Hib-HepB at 2, 3, 4 and 11 months of age. Pre- and one-month post-booster blood samples were collected for (functional) antibody titer analysis against 13 serotypes and four components of DTaP-IPV-Hib-HepB.

Results: Intention to treat analyses comparing PCV10 to PCV13 shows the following statistically significant differences for the shared serotypes. Higher pre-booster geometric mean concentrations (GMC) were seen for serotype 1, 6B, 9V, 18C and 23F and lower GMCs for serotype 19F. Post-booster GMCs were lower in PCV10 recipients for $6 / 10$ serotypes $(5,6 \mathrm{~B}, 9 \mathrm{~V}, 14,19 \mathrm{~F}$ and $23 \mathrm{~F})$. Post-booster geometric mean avidity index was higher for five serotypes and lower for two serotypes. The other serotypes were similar for both groups. Anti-pneumococcal opsonic activity is currently being analyzed.

Conclusion: Both PCV10 and PCV13 are immunogenic post-booster. While IgG persistence post-PCV10 priming was better for some serotypes, booster responses post-PCV13 for some serotypes were higher. These higher responses however were not associated with higher functional avidity. Both vaccines have proven effective in the field and the relevance of these subtle differences to long term protection requires further study.

Conflict of interest 


\title{
Poster Abstracts
}

ISPPD-0207

Next Generation Vaccines

\section{PROTECTION AGAINST LETHAL PNEUMOCOCCAL INFECTION OF MICE WITH THE IMMUNIZATION OF PNEUMOCOCCAL SURFACE PROTEIN A FUSION}

\author{
Z. Piao $^{1}$, Y. Akeda ${ }^{1}$, K.J. Ishii ${ }^{2}$, K. Ubukata ${ }^{3}$, D.E. Briles ${ }^{4}$, K. Tomono ${ }^{5}$, K. Oishi ${ }^{6}$ \\ ${ }^{1}$ Research Institute for Microbial Diseases, Osaka University, Osaka, Japan; ${ }^{2}$ Laboratory of Adjuvant Innovation, National Institute of Biomedi- \\ cal Innovation, Osaka, Japan; ${ }^{3}$ School of Medicine, Keio University, Tokyo, Japan; ${ }^{4}$ School of Medicine, University of Alabama at Birmingham, \\ Alabama, USA; ${ }^{5}$ School of Medicine, Osaka University, Osaka, Japan; ${ }^{6}$ Infectious Disease Surveillance Center, National Institute of Infectious Dis- \\ eases, Tokyo, Japan
}

Streptococcus pneumoniae is known to cause invasive pneumococcal diseases (IPD). Polysaccharide-based pneumococcal vaccines are currently available worldwide, however, it is difficult to protect the pneumococcal disease of all serotypes with polysaccharide-based vaccines. Moreover, it has been reported a number of IPD cases by non-vaccine serotypes in children after introduction of pneumococcal conjugate vaccine, and it implies a limitation of polysaccharide-based vaccine. To overcome this deficit, we have developed a novel pneumococcal vaccine based on pneumococcal surface protein $A(P s p A)$. PspA has been reported as a promising pneumococcal vaccine candidate, divided into 3 family and 6 clades. Immunization with one clade of PspA cannot protect the infection with pneumococci of other clades of PspA. Epitopes of PspA responsible for protective immunity have been reported, therefore, fusion proteins composed of different clades of PspA are conceived as cross-reactive antigens. Recombinant PspA fusions were examined for their cross-reactivity and protection against pneumococcal isolates with different PspA clades. Immunization with PspA fusion rendered significant protection in mice against pneumonia caused by strains with all five PspA clades tested. IgG-binding to clinical isolates from adult IPD patients was broadly higher in sera from mice immunized with successful PspA fusion than single PspA.

This study revealed that immunization with PspA fusion against pneumonia can cross-protect mice from lethal pneumonia caused by strains with a wide range of PspA clades, and this PspA fusion can be proposed as a novel pneumococcal protein vaccine to replace current capsular polysaccharide-based pneumococcal vaccines.

Conflict of interest

ISPPD-0177

Next Generation Vaccines

\section{SYNTHETIC HEXASACCARIDE - RELATED TO THE FRAGMENT OF THE CHAIN OF CAPSULAR POLYSACCHARIDE STREPTOCOCCUS PNEUMONIAE TYPE 14 AND DENDRITIC CELLS MATURATION}

\author{
E.A. Akhmatov ${ }^{1}$, E.A. Kurbatova ${ }^{1}$, D.S. Vorobiov ${ }^{1}$, E.V. Sukhova ${ }^{2}$, D.V. Yashunsky ${ }^{2}$, Y.E. Tsvetkov ${ }^{2}$, N.E. Nifantiev ${ }^{2}$ \\ ${ }^{1}$ Russian Academy of Medical Sciences, Mechnikov Research Institute for Vaccines and Sera, Moscow, Russia; ${ }^{2}$ Russian Academy of Sciences, \\ N. D. Zelinsky Institute of Organic Chemistry, Moscow, Russia
}

There is not enough information about the influence of synthetic hexasaccaride conjugates on the innate immunity system particularly on the dendritic cells (DC) maturation.

Aim: The research of dendritic cells maturation and their cytokine production in response to the glycoconjugate of synthetic hexasaccaride with BSA in vitro.

Methods: Preparation of hexasaccharide conjugate with BSA by a squarate approach. The Matrix-assisted Laser Desorption/Ionization Time of Flight (MALDI-TOF) mass-spectrum corresponded to inclusion into the conjugate of 18 hexasaccharide residues on average. DC was obtained from mice bone marrow and cultivated in RPMI-1640 with GM-CSF and IL-4. On day 6 into the culture medium was added $50 \mathrm{mkg} / \mathrm{ml}$ of glycoconjugate. Three days after incubation determined the surface molecules on the membrane of DC and cytokine production by flow cytometry. Results: It was revealed the decrease the number of undifferentiated CD34 ${ }^{+}$cells, but increasing the cells expressing adhesive $\mathrm{CD} 11 \mathrm{c}^{+}$, costimulatory $\mathrm{CD} 6^{+}$markers and $\mathrm{MHCl}^{+}$molecules of antigenic presentation, comparing with immature DC. It was not revealed the increase in number of cells, expressing the molecules of terminal differentiation - CD83+. In the culture medium appeared Th1 cytokines - IL-1 $\beta$, IL-17, TNF $\alpha$ and Th2 cytokines - IL-5, IL-6 on the background of decreasing GM-CSF.

Conclusion: Synthetic hexasaccaride - related to the fragment of the chain of capsular polysaccharide Streptococcus pneumoniae type 14 in complex with BSA induce the partly dendritic cells maturation and direct the immune response to Th1/Th2 way.

This work was supported by the Russian Foundation for Basic Research, project No. 11-04-01187.

No conflict of interest 
ISPPD-0176

Next Generation Vaccines

\title{
IMMUNOGENIC ACTIVITY OF A SYNTHETIC HEXASACCHARIDE FRAGMENT OF THE CAPSULAR POLYSACCHARIDE OF STREPTOCOCCUS PNEUMONIAE TYPE 14
}

\author{
E.A. Akhmatov ${ }^{1}$, E.A. Kurbatova ${ }^{1}$, D.S. Vorobiov ${ }^{1}$, E.V. Sukhova ${ }^{2}$, D.V. Yashunsky ${ }^{2}$, Y.E. Tsvetkov ${ }^{2}$, N.E. Nifantiev ${ }^{2}$ \\ ${ }^{1}$ Russian Academy of Medical Sciences, Mechnikov Research Institute for Vaccines and Sera, Moscow, Russia \\ ${ }^{2}$ Russian Academy of Sciences, N. D. Zelinsky Institute of Organic Chemistry, Moscow, Russia
}

Streptococcus pneumoniae type 14 is widely spread in human population, especially among children. Poor immunogenicity of its capsular polysaccharide (CP) and difficulties to isolate it by traditional methods for further including into pneumococcal vaccines could be overcome using the chemical synthesis.

Aim: The study of immunogenicity of a conjugate of a synthetic hexasaccharide fragment of the S.pneumoniae type 14 capsular polysaccharide with BSA.

Methods: The hexasaccharide conjugate was prepared by the squarate method and contained, according to the MALDI-TOF data, 18 hexasaccharide residues on average. Sera from mice after immunization with glycoconjugate absorbed on the aluminium hydroxide were tested in ELISA for detection IgG and its subisotypes to CP. The protective activity evaluated in experimental infection model.

Results: The optimal effective dose of the glycoconjugate that protected $100 \%$ of mice against S.pneumoniae type 14 was $10 \mathrm{mcg}$ (based on the hexasaccharide); $0.625 \mathrm{mcg}$ protected $87 \%$. The IgG to CP appeared in sera only after the second immunization, increased on day 14 to titer 1:9600 vs 1:200 before immunization and decreased to the day 60 . Booster injection elicited the rapid increase of $\operatorname{lgG}$ on the day 4 and up to day 90 they were determined in sera. The distribution of IgG subisotype to CP: IgG1 - 53.2\%; IgG2a-20.3\%; IgG2b-13.9\%; IgG3-12.2\%.

Conclusion: The synthetic hexasaccharide fragment of the capsular polysaccharide S. pneumoniae type 14 conjugated with BSA is immunogenic and induce immunological memory.

This work was supported by the Russian Foundation for Basic Research, project No. 11-04-01187.

No conflict of interest

ISPPD-0067

Next Generation Vaccines

\section{MULTIVALENT PNEUMOCOCCAL PROTEIN VACCINES COMPRISING PNEUMOLYSOID WITH EPITOPES/FRAGMENTS OF CbpA AND/OR PspA ELICIT STRONG AND BROAD PROTECTION}

A. Chen ${ }^{1}$, B. Mann², G. Gao ${ }^{2}$, R. Heath², J. King ${ }^{3}$, J. Maissoneuve ${ }^{4}$, M. Alderson ${ }^{4}$, A. Tate ${ }^{4}$, S.K. Hollingshead ${ }^{3}$, R.K. Tweten ${ }^{5}$, D.E. Briles ${ }^{3}$, E.I. Tuomanen', J.C. Paton ${ }^{1}$

${ }^{1}$ Research Centre for Infectious Diseases, University of Adelaide, Adelaide, Australia; ${ }^{2}$ Dept. Infectious Diseases, St Jude Children's Research Hos pital, Memphis, USA; ${ }^{3}$ Dept. Microbiology, University of Alabama at Birmingham, Birmingham, USA; ${ }^{4}$ Pneumococcal Vaccine Project, Path, Seattle, USA; ${ }^{5}$ Dept. Microbiology \& Immunology, University of Oklahoma Health Sciences Center, Oklahoma, USA

Background and Aims: Pneumolysin, choline-binding protein A ( $\mathrm{CbpA}$ ) and pneumococcal surface protein A (PspA) are proven protective immunogens against invasive pneumococcal disease in animal models. Here we test in different animal models the efficacy of a variety of multivalent vaccines comprising one or more of the following antigens: pneumolysin toxoid (L460D); L460D fused with protective peptide epitopes from CbpA (YPT-L460D-NEEK [YLN]); L460D fused with peptide CD2 containing the proline-rich region (PRR) of PspA (CD2-L460D); L460D + H70, a slightly larger PspA-derived peptide containing the PRR and the SM1 region; H70+YLN, and other combinations. Methods: Mice were immunized (IP or SC) three times with the various antigen combinations in alum adjuvant at 2-week intervals, and challenged in diverse mouse infection models with multiple Streptococcus pneumoniae strains.

Results: In the IP sepsis model, H70+YLN consistently showed significant protection against three different challenge strains (serotypes 1, 2 and 6A); significant protection was also elicited by CD2+YLN and H70+L460D combinations. Protection against IV sepsis (type 3 and 6A challenge strains) was largely dependent on PspA-derived antigen components and the best protection was elicited by H70, with or without either L460D or YLN. In a type 4 intratracheal challenge model resulting in progression to meningitis, the strongest protection was elicited by antigen combinations that contained YLN.

Conclusion: The antigen combination $\mathrm{H} 70+\mathrm{YLN}$ elicited the strongest and broadest protection in diverse pneumococcal challenge models.

No conflict of interest 
ISPPD-0095

Next Generation Vaccines

\section{IMMUNOGENICITY OF THE 13-VALENT PNEUMOCOCCAL CONJUGATE VACCINE (PCV13) IN PATIENTS WITH UNTREATED SMOLDERING MULTIPLE MYELOMA (MM) : A PILOT STUDY}

M. Bahuaud ${ }^{1}$, M. Malphettes ${ }^{2}$, H. Bodilis ${ }^{3}$, S. Park ${ }^{4}$, D. Bouscary ${ }^{4}$, F. Batteux ${ }^{1}$, O. Launay ${ }^{3}$, J.P. Fermand ${ }^{2}$

${ }^{1}$ Laboratoire d'Immunologie, Hôpital Cochin, Paris, France; ${ }^{2}$ Immuno-Hématologie Clinique, Hôpital Saint Louis, Paris, France; ${ }^{3} \mathrm{CIC}$ BT505, Hôpital Cochin, Paris, France; ${ }^{4}$ Hématologie Clinique, Hôpital Cochin, Paris, France

Background: Patients with multiple myeloma (MM) are at increased risk of invasive pneumococcal infections but the 23-valent pneumoccocal vaccine is poorly immunogenic in immunocompromised patients. The PCV13 is now available but data on its immunogenicity in patients with $\mathrm{MM}$ are needed.

Method: 20 patients with smoldering MM, received 1 dose of PCV13. Concentrations of IgG specific for 7 serotypes were measured at baseline, 1, 6 and 12 months after vaccination by standardized ELISA and Osponophagocytic Assay (OPA). Responses were defined as at least an IgG-two fold increased from baseline and $\geq 1 \mu \mathrm{g} / \mathrm{ml}$ by ELISA. Primary endpoint was the proportion of patients responding to at least more than half of the serotypes in ELISA at one month.

Results: At 1 month post vaccination, 12 patients (60\%) were responders in ELISA, among whom 10 were also responders in OPA, indicating functional antibodies. At 6 months, 7 (35\%) of the 12 responders had persistent immunity and only $4(20 \%)$ at 12 months. These results suggest a rapid lost of immunity.

\begin{tabular}{|c|c|c|c|c|c|}
\hline \multirow{3}{*}{ Serotypes } & \multicolumn{5}{|c|}{ Percentages of responders $(n-20)$} \\
\hline & \multicolumn{2}{|r|}{ M1 } & \multicolumn{2}{|c|}{ M6 } & M12 \\
\hline & ELISA & ELISA*OPA & ELISA & $E L / S A+O P A$ & ELISA \\
\hline 4 & 40 & 25 & 25 & 20 & 10 \\
\hline $6 \mathrm{~B}$ & 50 & 35 & 25 & 10 & 15 \\
\hline $9 \mathrm{~V}$ & 45 & 30 & 30 & 10 & 15 \\
\hline 14 & 65 & 40 & 65 & 30 & 45 \\
\hline $18 \mathrm{C}$ & 70 & 45 & 40 & 15 & 25 \\
\hline $19 \mathrm{~F}$ & 70 & 60 & 50 & 20 & 15 \\
\hline $23 \mathrm{~F}$ & 55 & 35 & 35 & 20 & 30 \\
\hline
\end{tabular}

Conclusion: One injection of the 13-valent pneumococcal conjugate vaccine (PCV13) is immunogenic in some patients with smoldering MM but most often incompletely and transiently. Repeated injections are likely to be needed for effective and sustained protection.

No conflict of interest

ISPPD-0476

Next Generation Vaccines

\section{DEVELOPMENT OF ADDITIONAL TARGET SEROTYPES FOR USE IN THE MULTIPLEXED OPSONOPHAGOCYTIC KILLING ASSAY (MOPA)}

R.L. Burton ${ }^{1}$, M.H. Nahm²

${ }^{1}$ Pathology, University of Alabama at Birmingham, Birmingham, USA; ${ }^{2}$ Pathology/Microbiology, University of Alabama at Birmingham, Birmingham, USA

Background: Opsonophagocytic assays (OPAs) for pneumococci were developed to provide information on the functionality of antibodies, unlike chemical-based assays such as ELISA. Recent improvements have increased the OPA throughput, and OPA data is now being required for licensure of pneumococcal vaccines. We have previously reported the development of a multiplexed OPA (MOPA) for Prevnar 13 serotypes. Here, we report the development of additional target serotypes that may be useful for evaluating new vaccine formulations.

Methods: The development of target strains and the MOPA protocol have been described previously (Burton and Nahm, 2006).

Results: We developed thirteen additional target strains for use in the MOPA, completing the serotypes covered by PPV23 (plus 6A, 6C, and 6D). During the characterization SPEC20, we found that type 20 PS from ATCC partially inhibited the killing of SPEC20, but completely inhibited the killing of an ATCC type 20 strain. The converse was observed with PS purified from a CDC strain, indicating some heterogeneity within serotype 20. During the characterization of other serotypes, we found significant non-specific killing (NSK) with multiple lots of baby rabbit complement (BRC). Adsorption of BRC with multiple pneumococcal strains, as well as other bacteria species, abrogated the NSK for all serotypes tested without affecting the hemolytic activity of the BRC.

Conclusion: The new target strains will allow evaluation of new vaccine formulations, and the presence of heterogeneity within serotype 20 should be considered for future vaccines. The long term effects of using adsorbed $\mathrm{BRC}$ in the MOPA must also be evaluated.

No conflict of interest 
ISPPD-0501

Next Generation Vaccines

\title{
DIFFERENT FERMENTATION STRATEGIES FOR PNEUMOCOCCAL WHOLE CELL VACCINE PRODUCTION AND THEIR IMPACT ON VACCINE QUALITY
}

\author{
I.B. Campos ${ }^{1}$, C.P. Cardoso Jr. ${ }^{2}$, F. Fratelli², M. Darrieux ${ }^{3}$, L.C.C. Leite ${ }^{1}$, R. Malley ${ }^{4}$, V.M. Gonçalves ${ }^{1}$ \\ ${ }^{1}$ Center of Biotechnology, Instituto Butantan, São Paulo, Brazil; ${ }^{2}$ Special Pilot Laboratory of Recombinant Biological Products, Instituto Butantan, \\ São Paulo, Brazil; ${ }^{3}$ Laboratório de Biologia Molecular e Farmacologia, Universidade São Francisco, Bragança Paulista, Brazil; ${ }^{4}$ Infectious Diseases, \\ Boston Children's Hospital, Boston, USA
}

Background and Aims: Our group developed the pneumococcal whole cell vaccine (WCV) production process using batch fermentation. This vaccine was immunogenic and protective in challenge assays. The aim of this study was to improve the production process in order to increase the WCV yield using different fermentation strategies and evaluate these preparations in a mouse model and in vitro analysis.

Methods: Batch, fed-batch and continuous fermentation with cell recycle were performed at $10 \mathrm{~L}$ scale. Cells were harvested at the highest optical density, washed and inactivated with $\beta$-propiolactone. C57BL/6 mice were immunized with these different preparations adsorbed to aluminum hydroxide. IgG antibody was measured by ELISA and whole-blood samples were stimulated to evaluate IL-17A production. Mice were challenged by aspirationsepsis model using WU2 strain. Antibody binding and opsonophagocytosis assay were performed using human isolated strains.

Results: Higher biomass yields were successfully achieved using the continuous fermentation with cell recycle, which produced a 3-fold higher yield than the batch strategy. All WCV produced were able to induce similar levels of IgG and a similar induction of IL-17A in vitro. Furthermore, these antibodies were able to bind different strains and induce pneumococcal opsonophagocytosis. Animal protection was afforded by the different WCV preparations $(\geq 80 \%)$, which was statistically different from the alum group $(0-20 \%)$.

Conclusion: Our results demonstrated that the different vaccine preparations displayed comparable protective properties. These results support the continuous process with cell recycle as a strategy for large scale WCV production for human immunization.

Acknowledgements: PATH, CNPq, Boston Children's Hospital, Butantan

No conflict of interest

ISPPD-0222

Next Generation Vaccines

\section{CHARACTERISATION OF A NOVEL HEAT SHOCK PROTEIN-ENRICHED MULTIVALENT STREPTOCOCCUS PNEUMONIAE} PROTEIN ANTIGEN VACCINE

\author{
W. Chan ${ }^{1}$, C. Bignell ${ }^{2}$, P. Cecchini ${ }^{2}$, C. Entwisle ${ }^{2}$, C. Bailey ${ }^{2}$, J. Brown $^{1}$ \\ ${ }^{1}$ UCL Respiratory, UCL, London, United Kingdom; ${ }^{2}$ ImmunoBiology Ltd., Babraham Research Campus, Cambridge, United Kingdom
}

Current vaccination against Streptococcus pneumoniae, using vaccines based on capsular polysaccharides from a limited number of serotypes, has led to serotype replacement. An alternative approach based on multiple protein antigens enriched with highly conserved heat-shock proteins (Hsps) may provide multivalent protection. Hsps are produced in response to cell stress and function as chaperones. By binding S. pneumoniae proteins they form Hsppeptide complexes which are directed to antigen presenting cells, improving both innate and adaptive immune responses. Bacterial lysates, enriched with Hsps from S. pneumoniae cultures subjected to stress (heat or acid shock), were purified to make a vaccine preparation. Vaccine efficacy was assessed in mice and rabbits. Western blotting, fluorescent surface IgG-binding assays and ELISAs were used to analyse serum antibody responses, and protective efficacy was assessed in a pneumonia model using colony-forming unit (CFU) counts from the lung. Hsp-enriched Rx1 strain-derived S. pneumoniae vaccines (V4, V5) induced robust antibody responses in mouse and rabbit models. Rabbit sera contained cross-reactive antibodies against multiple serotypes, including non-vaccine serotypes (Figure 1.), and sera from vaccinated mice opsonised S. pneumoniae with IgG. In the pneumonia model, the vaccine significantly protected against homologous infection, with approximately one log10-fold fewer CFU in the lungs than in control mice. These novel vaccines induced production of cross-reactive antibodies against multiple serotypes of $S$. pneumoniae and protected against challenge in the pneumonia model. This vaccine approach has the potential to provide broad serotype-independent protection against S. pneumoniae. 


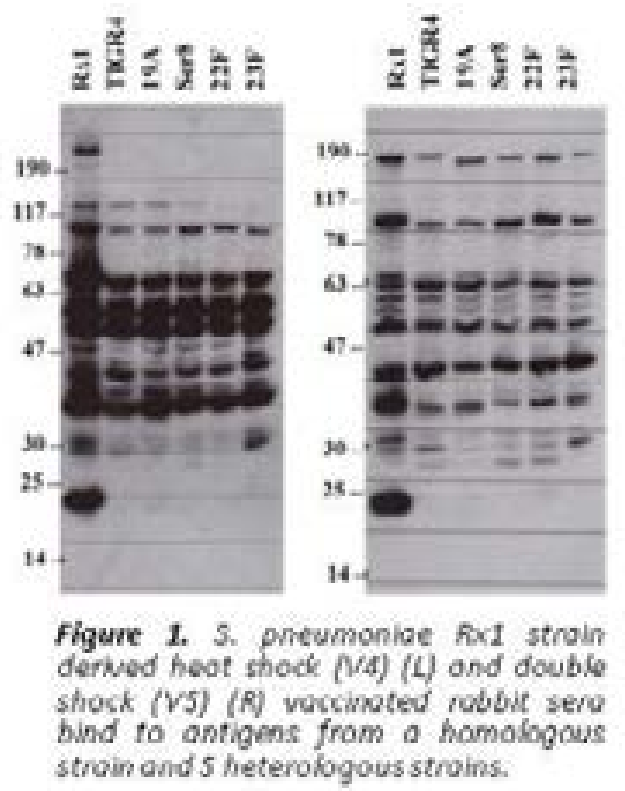

No conflict of interest

ISPPD-0558

Next Generation Vaccines

\section{ESTIMATING THE VALUE OF PNEUMOCOCCAL CONJUGATE VACCINATION IN INDIA: STATE-LEVEL AND NATIONAL- LEVEL ANALYSES}

D. Constenla ${ }^{1}$, T. Liư ${ }^{1}$, N.K. Arora ${ }^{2}$

${ }^{1}$ International Health, Johns Hopkins Bloomberg School of Public Health, Baltimore, USA; ${ }^{2}$ Executive Office, The INCLEN Trust International \& CHNRI, Delhi, India

Background and Aims: Streptococcus pneumoniae is a leading cause of childhood pneumonia and meningitis morbidity/mortality in India. Our objective was to project the health/economic benefits of achieving high coverage of pneumococcal conjugate vaccine (PCV) in India.

Methods: We adapted an existing model and synthesized locally available data to estimate the potential impact of PCV in India and selected states (Bihar, Delhi, Maharashtra, Tamil Nadu) in terms of averting: deaths/cases, disease costs and productivity loss for a single year with three theoretical coverage scenarios for PCV (72\%, 80\%, 90\%). Sensitivity analyses were performed to evaluate the impact of model assumptions.

Results: PCV in India could result in \$427million (range \$188.1-\$19.3million) of cost savings to the public sector in a single year. Up to $\$ 2.4$ million of these savings is attributable to averted treatment costs and $\$ 67.4 \mathrm{million}$ to meningitis-related productivity loss averted. Caretaker productivity and transportation costs averted accounted for $\$ 1.2$ million in savings. Averted lost productivity due to premature death represented $83 \%$ of these savings at $\$ 355.9$ million. The greatest savings to the public sector (\$57.4million) occurred in Bihar where the burden of disease is high, followed by Maharashtra with \$7million and Delhi with \$2.5million. For the private sector in India, the benefits of achieving $90 \%$ of PCV in a single year result in $\$ 1.7$ billion savings. For Bihar, Maharashtra and Delhi, savings to the private sector translated into $\$ 225$ million, $\$ 27.5$ million and $\$ 10.7$ million, respectively.

Conclusion: Achieving high coverage of PCV results in substantial cost savings to the public and private sectors in India.

No conflict of interest 
ISPPD-0194

Next Generation Vaccines

\title{
EVALUATING THE COST-EFFECTIVENESS OF VACCINE AGAINST PNEUMOCOCCAL DISEASE IN NIGERIA
}

D. Constenla ${ }^{1}$, D. Erchick ${ }^{1}$, C. Wonodi ${ }^{1}$

${ }^{1}$ International Health, Johns Hopkins Bloomberg School of Public Health, Baltimore, USA

Background: Streptococcus pneumoniae is a leading cause of childhood pneumonia and meningitis deaths in Nigeria.

Objective and Methods: We adapted an existing economic model and synthesized available data to estimate the incremental cost-effectiveness of a pneumococcal conjugate vaccination program for Nigeria over the period 2012-2031, using a government perspective. The main outcome measures considered: 1) the healthcare costs of pneumococcal disease; 2 ) the disease burden and healthcare system costs averted by vaccination; 3 ) the disabilityadjusted life year (DALY) averted; and (4) the life saved or death averted by vaccination. For this analysis indirect effects of the vaccine, which likely result in greater vaccine impact, and potential serotype replacement were not considered. Sensitivity analyses were performed to evaluate the potential impact of the uncertainty of estimates. Results: Pneumococcal vaccination at the rate of diphtheria-tetanus-pertussis vaccine coverage was projected to prevent 265,225 pneumococcal cases and 8,980 pneumococcal deaths per year in children aged $<5$ years in Nigeria, or approximately one life saved per 1,000 infants vaccinated. These saved lives and averted cases of deafness, motor deficit, and seizure resulted in 413,238 DALYs averted annually. At vaccine prices between US\$5 and US\$15 per dose, the cost per DALY averted from a governmental perspective ranged from US\$16 to US\$50. Sensitivity analyses showed changes in vaccine efficacy and vaccine cost exerted the greatest influence on the study results. Conclusion: Vaccination against pneumococcal disease was highly cost-effective in Nigeria, based on WHO standards for evaluating the economic value of health interventions.

No conflict of interest

ISPPD-0102

Next Generation Vaccines

\section{EVALUATION OF THE IMMUNE RESPONSE INDUCED AGAINST rPOTD, rPdT AND THE HYBRID PROTEIN rPotD-PdT}

\author{
T.R. Converso ${ }^{1}$, C. Goulart ${ }^{1}$, D. Rodriguez ${ }^{2}$, M. Darrieux ${ }^{3}$, L.C.C. Leite ${ }^{2}$
}

${ }^{1}$ Biotecnologia, Instituto de Ciências Biomédicas University of São Paulo, São Paulo, Brazil; ${ }^{2}$ Centro de Biotecnologia, Instituto Butantan, São Paulo, Brazil; ${ }^{3}$ Laboratório de Biologia Molecular e Farmacologia, Universidade São Francisco, Bragança Paulista, Brazil

Background and Aims: In order to increase the width of protection of the current pneumococcal vaccines, several pneumococcal proteins have been investigated as vaccine candidates. PotD is a surface exposed, membraneassociated conserved protein that works in the transport of extracellular polyamines to the intracellular environment. PdT is a detoxified form of pneumolysin, a conserved protein present in all pneumococcal isolates with possible adjuvant activity. The aim of this study was to evaluate the immunological response induced by mouse immunization with rPotD, rPdT and the hybrid protein rPotD-PdT.

Methods: The potD gene was amplified by PCR and inserted into the pET-28a expression vector. The potD-pdT hybrid was generated by ligation of pdT gene into $\mathrm{pET}$-28a-poTD vector. The recombinant proteins were expressed in Escherichia coli and purified by affinity chromatography. BALB/c mice were immunized with 3 doses of the proteins at 15 days intervals. Antibody production was evaluated by ELISA. Immunized animals were sacrificed and the peritoneal and spleen cells were cultured for evaluation of NO production. Cytokine production was evaluated by flow cytometry using CBA.

Results: Mouse immunization with the recombinant proteins induced the production of specific antibodies against rPotD, while a significant increase in cytokine and NO was observed in peritoneal and spleen cells after stimulation with rPotD and rPdT.

Conclusion: These results suggest that the rPotD-PdT hybrid protein is immunogenic and able to elicit both humoral and cellular responses against at least one protein, but requires a better understanding of its protection mechanism.

Supported by FAPESP and Fundação Butantan.

No conflict of interest 


\title{
ISPPD-0445
}

Next Generation Vaccines

\section{MICE IMMUNIZATION WITH A PSPA-PIy HYBRID VACCINE IS PROTECTIVE AGAINST PNEUMOCOCCAL PNEUMONIA}

\author{
D. Rodriguez ${ }^{1}$, C. Goulart ${ }^{1}$, T.W. Santos ${ }^{2}$, J.A. Pereira ${ }^{3}$, C.A.R. Martinez ${ }^{3}$, L.C.C. Leite ${ }^{1}$, H.K. Rofatto ${ }^{4}$, M. Darrieux ${ }^{5}$
}

${ }^{1}$ Centro de Biotecnologia, Instituto Butantan, Sao Paulo, Brazil; ${ }^{2}$ Programa de Pós-graduação Interunidades em Biotecnologia, Universidade de São Paulo, Sao Paulo, Brazil; ${ }^{3}$ Biologia Molecular e Farmacologia, Universidade São Francisco, Bragança Paulista, Brazil; ${ }^{4}$ Laboratorio de Parasitologia, Instituto Butantan, Sao Paulo, Brazil; ${ }^{5}$ Molecular Biology and Farmacology, São Francisco University, Bragança Paulista, Brazil

Background and Aims: Pneumococcal surface protein A (PspA) and pneumolysin (Ply) are two important vaccine candidates, able to elicit protection in different models of pneumococcal infection. The high immunogenic potential of PspA, combined with a possible adjuvant effect of pneumolysin (due to its ability to interact with TLR-4) could greatly improve the immunogenicity and coverage of a protein-based pneumococcal vaccine. The combination of PspA and the pneumolysin derivative PID1 has been shown to induce the production of high antibody levels against each protein, and to protect mice against invasive challenge. The aim of the present study was to investigate the cellular response induced by such vaccine, and to evaluate protection in a model of focal pneumococcal pneumonia. Methods: A model of focal pneumococcal pneumonia was developed in BALB/c mice by nasal instillation of a high dose of a serotype 14 strain with low virulence. Airway inflammation was confirmed by total and differential cell counts in BAL and by histological analysis of the lungs, and bacterial loads were measured 7 days after challenge. Cytokine levels were determined in the BALF and lungs of mice immunized with PspA-PID1 fusion after challenge, by flow cytometry and RT-PCR, respectively.

Results: After challenge, the mice developed lung inflammation with no invasion of other sites, as demonstrated by histological analysis of lung tissue. We detected a significant production of TNF- $\alpha$ and IL- 6 in the BALF which correlated with protection against pneumonia in the group immunized with PspA-PID1.

Conclusion: PspA-PID1fusion is protective against invasive infections and pneumonia in mice. Supported by FAPESP.

No conflict of interest

ISPPD-0284

Next Generation Vaccines

\section{DEVELOPMENT OF ANTIBODIES TO PNEUMOCOCCAL COMMON PROTEIN ANTIGENS (CPAS) AND THEIR ASSOCIATION WITH HIV AND NASOPHARYNGEAL COLONIZATION IN AFRICAN INFANTS}

\author{
Z. Ditse ${ }^{1}$, P.V. Adrian ${ }^{1}$, L. Kuwanda' ${ }^{1}$, S.A. Madhi ${ }^{2}$
}

${ }^{1}$ Respiratory Meningeal Pathogens Research Unit, University of the Witwatersrand Faculty of Health Sciences DST/NRF Vaccine Preventable Diseases, Johannesburg, South Africa; ${ }^{2}$ Centre for Vaccines and Immunology, National Institute for Communicable Diseases - Division of National Health Laboratory Service, Sandringham, South Africa

This study aimed to characterize the natural kinetics of serum IgG titres to 15 CPAs in relation to maternal HIV exposure. We also explored the association between common protein antigen (CPA) antibody titres and pneumococcal nasopharyngeal colonization in children at 4, 10, 18 and 24 months of age.

Methods: IgG titres to CPAs were measured with a 15-plex Luminex assay for the following proteins: PspA, PspC, LytB, IgA1-proteinase, SP0082, PdB, PcsB, PsaA, SP0609, SP0749, PpmA, SlrA, StkP, SP2027 and SP2194. Serum samples and nasopharyngeal swabs from children at 4, 10, 18 and 24 months of age were analysed.

Results: The study included $125 \mathrm{HIV}$-unexposed, uninfected (HUU) and 125 HIV-exposed, uninfected (HEU) children. Higher titres against PspA, PspC, LytB, PpmA, PcsB, StkP, PdB and SP0082 were observed in HUU compared with $\mathrm{HEU}$ and also showed an increase with age. In contrast, lower antibody titres against PsaA and SP0609 were evident in HUU compared with HEU children. Higher titres were also observed in the pneumococcal-colonized children compared with -uncolonized children for PdB, SP0082, LytB, PpmA, PcsB and StkP. Higher antibody titres against SP2027, SP0749 and SP2194 were associated with absence of colonization.

Conclusion: Natural immunity to CPAs develops early in life, and is associated with pneumococcal colonization for some CPAs. SP2027, SP0749 and SP2194 CPAs are potential vaccine-candidates which may protect against pneumococcal colonization and consequently pneumococcal disease. Serum IgG antibodies to other studied CPAs warrant further evaluation with regards to their association with colonization later in life and potential for protecting against pneumococcal disease.

No conflict of interest 
ISPPD-0110

Next Generation Vaccines

\title{
IMMUNOGENICITY OF A NEW CUBAN PNEUMOCOCCAL CONJUGATE VACCINE: A PHASE I CLINICAL TRIAL IN CHILDREN
}

D. García-Rivera ${ }^{1}$, L. Rodríguez-Noda ${ }^{1}$, A. Pérez-Baños ${ }^{1}$, C.P. Dotres-Martínez ${ }^{2}$, R. Puga-Gomez ${ }^{2}$, Y. Soroa-Millán ${ }^{1}$, B. Paredes-Moreno ${ }^{3}$, N. González-García ${ }^{3}$, S. Rosell-León ${ }^{3}$, Y. Rodríguez-Estrada ${ }^{1}$, M.A. Alvarez-García ${ }^{3}$, A. IglesiasMachado ${ }^{3}$, M.C. Esquivel-Pedroso ${ }^{2}$, D. Santana-Mederos ${ }^{1}$, Y. Valdés-Balbín ${ }^{1}$, P. Burbidge ${ }^{4}$, M. Johnson ${ }^{4}$, D. Goldblatt ${ }^{4}$, V. Vérez-Bencomo ${ }^{1}$

${ }^{1}$ Immunology, Center for Biomolecular Chemistry, Havana, Cuba; ${ }^{2}$ Pediatrics, Pediatric Hospital “Juan Manuel Marquez", Havana, Cuba; ${ }^{3}$ Clinical Trials, Center for Biomolecular Chemistry, Havana, Cuba; ${ }^{4}$ Immunology, UCL Institute of Child Health, London, United Kingdom

A new conjugate vaccine containing seven serotypes of Streptococcus pneumoniae (PCV7-TT) has been designed in Cuba. PCV7-TT contains $2 \mu \mathrm{g}$ of capsular polysaccharide from serotypes 1, 5, 14, 18C, 19F and $23 \mathrm{~F}$ and $4 \mu \mathrm{g}$ of $6 \mathrm{~B}$ conjugated to tetanus toxoid (TT). A phase I, parallel, controlled and double blind clinical trial was designed to assess the safety of PCV7 in fifteen 4-5 years old children. Children were randomised to receive one dose of PCV7-TT $(n=10)$ or Synflorix $(n=5)$. Post-vaccination, children were followed for 30 days to assess adverse events. Serum was obtained before and 30 days after vaccination for assessment of immunogenicity. Serotype specific opsonophagocytic assay (OPA) and ELISA were performed at the WHO Reference Laboratory, UCL Institute of Child Health. The primary outcome of this study was safety but immunogenicity was explored. PCV7-TT showed a good safety profile. Pre-vaccination, the number of subject with OPA $\geq 8$ was: 0\% (Sp1, Sp5), $13 \%$ (Sp18C, Sp19F), 30\% (Sp6B, Sp23F), 66\% (Sp14). Post-vaccination, IgG GMC and OPA GMT for the seven shared serotypes were comparable between the groups. $100 \%$ of children from both groups had OPA $>8$ for serotypes $6 \mathrm{~B}, 14,18 \mathrm{C}$, 19F, 23F; and between 40-70\% for serotypes 1 and 5. Despite the small sample of this study, these are the first immunogenicity data generated for this new vaccine in children. These results pave the way for further clinical trials in children and infants.

No conflict of interest

ISPPD-0552

Next Generation Vaccines

\section{SEROTYPES AND ANTIBACTERIAL SUSCEPTIBILITIES OF STREPTOCOCCUS PNEUMONIAE ISOLATED FROM ADULT WITH INVASIVE AND NONINVASIVE INFECTIONS IN ISTANBUL MEDICINE OF FACULTY}

\author{
N. Gurler ${ }^{1}$, L. Oksuz ${ }^{1}$ \\ ${ }^{1}$ Department of Medical Microbiology, Istanbul University Istanbul Faculty of Medicine, Istanbul, Turkey
}

Background and aims: Streptococcus pneumoniae is one of the most important pathogens in bacterial pneumoniae, sepsis and meningitidis in the world. Resistance of $S$. pneumoniae is increasing to penicillin and other antibiotics. The introduction of pneumococal vaccines has decreased the rate of pneumococcal diseases and resistance to antibotics. The aim of this study was to evaluate the serotypes and antimicrobial susceptibilities of invasive $S$. pneumoniae strains isolated from adult patients in Istanbul Medicine of Faculty.

Methods: S. pneumoniae isolates were isolated from adult patients in Istanbul Medicine of Faculty. A total of 103 S. pneumoniae isolates were isolated from sputum, blood and other steril body fluids of adults with invasive/ noninvasive pneumococcal disease. Antibiotic susceptibility tests for penicilin $\mathrm{G}$ and cefotaxime were performed according to the guidelines of the Clinical and Laboratory Standards Institute (CLSI). Serotyping was performed by the Quellung reaction using serotype-specific antisera (Statens Serum Institut, Denmark).

Results: The mean age of the patients was 55.6 \pm 17.8 . Among 103 invasive/noninvasive $S$. pneumoniae isolates $46 \%$ were isolated from sputum, $31 \%$ from blood and the rest from other specimens (pus, pleural fluid, vitreus fluid, peritoneal fluid, bronchoalveolar lavage fluid, etc). The rate of resistance to the antibiotics was too low: Three $(3 \%)$ of the isolates were intermediate to cefotaxime and only one (1\%) isolate to penicilin $\mathrm{G}$. The most common serotypes among 103 strains were $3(23 \%), 19 \mathrm{~F}(11 \%), 8(6 \%), 14(6 \%), 23 \mathrm{~F}(6 \%), 6 \mathrm{~A}(5 \%), 19 \mathrm{~A}(4 \%)$. Fifteen (15\%) of the isolates have nonvaccine serotypes. The coverage of PCV13 was $68.4 \%$.

Conclusion: Resistance to penicillin was lower in adult patients. The serotypes of our patients were compatible with serotypes in PCV13.

No conflict of interest 
ISPPD-0543

Next Generation Vaccines

\title{
ENHANCED SURVEILLANCE OF INVASIVE PNEUMOCOCCAL DISEASE IN THE KATHMANDU VALLEY, NEPAL, FROM 2005 TO 2012
}

\author{
M. Gurung ${ }^{1}$, S. Thorson ${ }^{1}$, R. Kandasamy ${ }^{2}$, N. Adhikary ${ }^{1}$, S. Shrestha ${ }^{1}$, V.B. Veeraraghavan ${ }^{3}$, M.D. Snape ${ }^{4}$, D.F. Kelly ${ }^{2}$, \\ D.R. Murdoch ${ }^{5}$, A. Pollard ${ }^{2}$ \\ ${ }^{1}$ Paediatric Department, Patan Hospital, Kathmandu, Nepal; ${ }^{2}$ Paediatric Department, University of Oxford, Oxford, United Kingdom; ${ }^{3}$ Microbiolo- \\ gy Department, Christian Medical College, Vellore, India; ${ }^{4}$ Paediatric Department, Oxford University, Oxford, United Kingdom; ${ }^{5}$ Microbiology De- \\ partment, University of Otago, Christchurch, New Zealand
}

Background: The serotype-specific range of invasive pneumococcal disease has significant geographic variations. Accurate depiction of this spectrum and its distribution according to age is integral to maximising the impact of pneumococcal conjugate vaccines in specific settings.

Methods: With funding initially from PneumoADIP and subsequently through the World Health Organisation an ongoing programme of enhanced pneumococcal disease surveillance is being conducted at Patan Hospital, Kathmandu, Nepal. Invasive pneumococcal disease isolates cultured from sterile body sites of children up to 14 years of age, presenting to the hospital underwent molecular serotyping by PCR.

Results: Between April 2005 and September 2012, 84 children had pneumococcus isolated from cultures, with 22 different serotypes identified. The greatest proportion of isolates $(0.23,95 \% \mathrm{Cl} 0.19-0.42)$ were from children less than 9 months of age followed by those $9-18$ months of age $(0.11,95 \% \mathrm{Cl} 0.08-0.25)$. In children under 5 years of age the highest proportion of total isolates that are serotypes in the 13-valent pneumococcal conjugate vaccine were seen in the $27-36$ month age range $(1,95 \% \mathrm{Cl} 0.54-1)$ and the lowest in the $0-9$ month age range $(0.42,95 \% \mathrm{Cl}$ 0.39-0.94).

Conclusions: Only a small proportion of pneumococcal conjugate vaccine serotypes are responsible for disease in early infancy, followed by a dramatic shift towards vaccine serotypes, particularly serotype 1, beyond early infancy and into childhood. A vaccine strategy that provides protection beyond early infancy would have the greatest impact in this setting.

No conflict of interest ISPPD-0092

Next Generation Vaccines

\section{SAFETY AND IMMUNOGENICITY OF AN INVESTIGATIONAL 12-VALENT PNEUMOCOCCAL NON-TYPEABLE HAEMOPHILUS INFLUENZAE PROTEIN D CONJUGATE VACCINE IN TODDLERS: PHASE I STUDY}

M. Horn ${ }^{1}$, G. Bleckmann², M. Traskine ${ }^{3}$, J. Rüggeberg ${ }^{3}$, K. Dobbelaere ${ }^{3}$, D. Borys ${ }^{3}$

${ }^{1}$ Pediatric Office Dr. med. Michael Horn, Berchtesgaden, Germany; ${ }^{2}$ Private Practice, Baunatal, Germany; ${ }^{3}$ Vaccine Discovery and Development, GlaxoSmithKline Vaccines, Wavre, Belgium

Background and Aims: We assessed the safety and immunogenicity of an investigational 12-valent pneumococcal non-typeable Haemophilus influenzae protein D conjugate vaccine (12vPHiD-CV) containing 10 serotype-specific conjugates common to the licensed 10 -valent vaccine (PHiD-CV) plus 6A and $19 \mathrm{~A}-\mathrm{CRM}^{197}$ conjugates. Methods: In this phase I, double-blind study (NCT01485406), 61 toddlers (12-23 months old), who previously completed 3-dose PHiD-CV primary vaccination, were randomized (1:1) to receive a dose of 12vPHiD-CV or PHiD-CV. Solicited/unsolicited adverse events (AEs) (within 7/31 days post-vaccination, respectively) and serious AEs (SAEs) were recorded. Primary objective: occurrence of vaccination-related SAEs and grade 3 AEs. Serological assessment was performed pre- and 1 month post-vaccination.

Results: Vaccination-related grade 3 solicited AEs were reported in 5 12vPHiD-CV recipients (2 [6.5\%] with redness; 3 [9.7\%] with swelling) and 3 PHiD-CV recipients (1 [3.4\%] each with swelling, irritability or fever). No grade 3 vaccination-related unsolicited AEs or SAEs were reported. The most frequent solicited AEs were redness and irritability. 58.1\% (12vPHiD-CV) and 50.0\% (PHiD-CV) toddlers had $\geq 1$ unsolicited AE. Post-vaccination, for each of the common vaccine serotypes, all toddlers had antibody concentrations $\geq 0.2 \mu \mathrm{g} / \mathrm{mL}$. For $6 \mathrm{~A}$ and $19 \mathrm{~A}$, all $12 \mathrm{vPHiD}-$ CV recipients and $\geq 84.6 \% \mathrm{PHiD}-\mathrm{CV}$ recipients had post-vaccination antibody concentrations $\geq 0.2 \mu \mathrm{g} / \mathrm{mL}$ (Table). Pneumococcal and protein $D$ antibody concentrations increased from pre- to post-vaccination in both groups (Table).

Conclusion: 12vPHiD-CV was well-tolerated and immunogenic in PHiD-CV-primed toddlers

Funding: GlaxoSmithKline Biologicals SA 


\begin{tabular}{|c|c|c|c|c|c|c|c|c|}
\hline \multirow[t]{2}{*}{ Avilieth } & \multicolumn{4}{|c|}{ 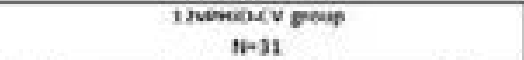 } & \multicolumn{4}{|c|}{$\begin{array}{l}\text { Friber groap } \\
N-2 ?\end{array}$} \\
\hline & $A_{m}$ & Pent & Ane & Fent & Pre & Pen & $p m$ & Feat \\
\hline \multicolumn{9}{|c|}{ 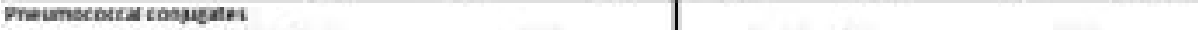 } \\
\hline & \multicolumn{2}{|c|}{$\$ 20.2 \mathrm{uc} / \mathrm{ml}$} & \multicolumn{2}{|c|}{ CMC } & \multicolumn{2}{|c|}{ K $20.2 \mathrm{ws} / \mathrm{mt}$} & \multicolumn{2}{|c|}{ CME } \\
\hline $1+0$ & $\begin{array}{c}\text { C5.3 } \\
(43+66=2)\end{array}$ & $\frac{100}{12 a-466)}$ & $\begin{array}{c}0.26 \\
(0.19=0.34)\end{array}$ & $\begin{array}{c}2.14 \\
125-2.26\end{array}$ & $\begin{array}{c}\text { A1. } \\
4.2-45.4\end{array}$ & $\begin{array}{c}100 \\
10+2+-106\end{array}$ & $\frac{0.11}{16.22-428}$ & 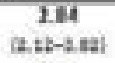 \\
\hline 410 & $\begin{array}{c}67.9 \\
(47.0-9.15)\end{array}$ & $\begin{array}{c}100 \\
\text { ise. }\end{array}$ & 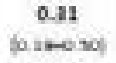 & ${ }_{3.60-1.00}^{5.18}$ & $\begin{array}{c}57.7 \\
\text { bo.m-9e. }\end{array}$ & $\begin{array}{c}100 \\
|07.2 * 100|\end{array}$ & $\begin{array}{c}0.3 n \\
10.19-0.4 z \mid\end{array}$ & $\begin{array}{c}4.52 \\
0.34-8.201\end{array}$ \\
\hline $3+5$ & $\begin{array}{c}690 \\
{[a b:-64]}\end{array}$ & $\frac{106}{120.5-i 66 \mid}$ & $\begin{array}{c}0.34 \\
10.23-4.4 \%\end{array}$ & $\begin{array}{c}3.31 \\
{[1.34-431}\end{array}$ & $\begin{array}{c}62.5 \\
(40.6-2.2 .7\end{array}$ & 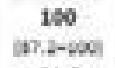 & $\begin{array}{c}0.32 \\
10.21-0.301\end{array}$ & 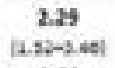 \\
\hline GA-CKastas" & 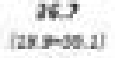 & $\frac{200}{\text { ares-i0es }}$ & $\begin{array}{c}0.17 \\
\text { a.12uen }\end{array}$ & $\begin{array}{c}5.97 \\
\text { anmani }\end{array}$ & $\frac{20.0}{12000 . \pi}$ & $\frac{21.6}{\ln 2.200 .65}$ & $\begin{array}{c}0.08 \\
0.00-0.241\end{array}$ & $\begin{array}{c}0.35 \\
0.20-2 \pi t\end{array}$ \\
\hline $\operatorname{sep0}$ & $\begin{array}{c}66.7 \\
\text { (4) } x-62.7\end{array}$ & $\begin{array}{c}100 \\
|a m-100|\end{array}$ & $\underset{20.21}{21-<40}$ & $\begin{array}{c}5.27 \\
(400-7.14)\end{array}$ & $\ln _{12-15.4}^{4.7}$ & $\begin{array}{c}100 \\
\operatorname{mon} 2-200 \mid\end{array}$ & $\frac{0.20}{(0.25-0.30 \mid}$ & $\begin{array}{c}1.92 \\
a .90-2.401\end{array}$ \\
\hline$\pi+0$ & $\begin{array}{c}36.7 \\
(150.5=60.2)\end{array}$ & $\begin{array}{c}100 \\
\text { [as. }-5=200 \mid\end{array}$ & $\begin{array}{c}0.80 \\
0.970-136\end{array}$ & $\begin{array}{c}3.76 \\
(1.4-4)\end{array}$ & $\cos ^{95.8}$ & $\begin{array}{c}100 \\
(0>2)-200 \mid\end{array}$ & $\begin{array}{c}0.65 \\
10.45-0.06\end{array}$ & $\begin{array}{c}3.36 \\
\text { (2.45-4.92) }\end{array}$ \\
\hline wN $=0$ & $\begin{array}{c}90.0 \\
{[725-979)}\end{array}$ & $\begin{array}{c}100 \\
\text { [3s. } 6-100 \text { ] }\end{array}$ & $\begin{array}{c}0.70 \\
\mid 0.40-0.61\end{array}$ & $\begin{array}{c}4.28 \\
0.27 \times-2.60\end{array}$ & $\begin{array}{c}83-3 \\
\mid 02.6-23.3)\end{array}$ & $\begin{array}{c}160 \\
\text { in. } 2=-600\end{array}$ & $\begin{array}{c}0.59 \\
(0.54-100)\end{array}$ & $\begin{array}{c}3.61 \\
\text { a. } 58-2.46 \mid\end{array}$ \\
\hline 2400 & 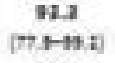 & $\frac{100}{|a n:-106|}$ & $\begin{array}{c}0.94 \\
|0.00-1.40|\end{array}$ & $\frac{1.30}{(0.25-10.9 n\}}$ & $\underset{(\pi 20-9)}{91.7}$ & $\begin{array}{c}100 \\
(07.2-190)\end{array}$ & $\begin{array}{c}0.41 \\
\mid 0.4-1.21\end{array}$ & $\underset{\mid 2.3 i-1.25}{7.15}$ \\
\hline 1enc $\pi$ & $\lim _{\ln : 4}$ & 100 & $\begin{array}{c}0.53 \\
|0.43-201|\end{array}$ & $\stackrel{11.26}{\mid 2.11-38.26}$ & $\begin{array}{c}74.2 \\
\mid x+8.02 .4\end{array}$ & $\begin{array}{c}100 \\
\text { m. } 2 \text { : tse }\end{array}$ & coss & $\begin{array}{c}11.17 \\
\mid 7.00-18.28]\end{array}$ \\
\hline arecuenar" & $\begin{array}{c}\text { Ms. } \\
|4 \times 2-42.7|\end{array}$ & $\begin{array}{c}100 \\
(\text { anc-sas) }\end{array}$ & 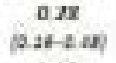 & 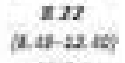 & $\cos _{0.20}$ & 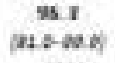 & $\begin{array}{c}0.13 \\
(0.25-2.24)\end{array}$ & $\begin{array}{c}1.95 \\
12.28 .2 .2 \%\end{array}$ \\
\hline 19. & $\begin{array}{c}\text { as.s } \\
\text { [6s. } 1-0,4 \text { ) }\end{array}$ & $\frac{100}{|11.2-406|}$ & $\frac{1.18}{|0.60-2.06|}$ & $\begin{array}{c}17.34 \\
{[2.00-14.57)}\end{array}$ & $\begin{array}{c}91 . T \\
(0.8-00.6)\end{array}$ & $\begin{array}{c}100 \\
\text { m. }\end{array}$ & $\begin{array}{c}0.57 \\
10.06-0.00\end{array}$ & $\begin{array}{c}10.59 \\
\text { (1.60-4.76) }\end{array}$ \\
\hline zston & $\begin{array}{c}70.0 \\
(90.6-13.9]\end{array}$ & 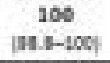 & $\begin{array}{c}0.56 \\
10.23-4.49\end{array}$ & $\begin{array}{c}3.46 \\
12.83-1.34\end{array}$ & $\begin{array}{c}\pi, 0 \\
0.9019\end{array}$ & $\begin{array}{c}100 \\
17.2-100 \\
\end{array}$ & 0.00 & 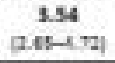 \\
\hline Frotein D & \multicolumn{2}{|c|}{ \$aboo R.W/m } & \multicolumn{2}{|c|}{ GNC } & \multicolumn{2}{|c|}{$\$ a 100$ a.uini } & \multicolumn{2}{|c|}{ ENC } \\
\hline & 0.3 & 36.8 & 316 & 1634 & 7.2 & 100 & 244 & 1433 \\
\hline & (93)-34.41 & (13)-233) & (210-47t) & 112127-zant & (975-2231 & $1211-200$ & (134-393) & | \\
\hline
\end{tabular}

Conflict of interest

ISPPD-0016

Next Generation Vaccines

\section{IDENTIFICATION AND FUNCTIONAL CHARACTERIZATION OF PROTECTIVE ANTI-PNEUMOCOCCAL SURFACE PROTEIN A MONOCLONAL ANTIBODIES}

N. Khan ${ }^{1}$, R.A. Qadri ${ }^{2}$, D. Sehgal ${ }^{3}$

${ }^{1}$ Molecular Immunology Laboratory, National Institute of Immunology New Delhi, Department of Biotechnology, University of Kashmir, Srinagar, India; ${ }^{2}$ Department of Biotechnology, University of Kashmir, Srinagar, India; ${ }^{3}$ Molecular Immunology Laboratory, National Institute of Immunology, New Delhi, India

Pneumococcal surface protein $\mathrm{A}(\mathrm{PspA})$ is a polymorphic cell surface choline binding protein. PspA is an antigenically variable virulence factor and has been classified based on its sequence into three families and six clades. Previously, we reported the molecular characterization of monoclonal antibodies (mAbs) directed against the extracellular domain (without proline rich region) of PspA from strain R36A. We found that the relative avidity of the primary IgG anti-PspA polyclonal antibodies was higher in serum of mice immunized with heat-killed R36A compared to recombinant PspA. Epitope localization and competition experiments suggested that anti-PspA mAbs bind at least 12 topographically distinct epitopes. Here we report the identification and functional characterization of anti-PspA mAbs that confer protection. We evaluated 18 anti-PspA mAbs that were raised from heat-killed R36A immunized mice and were of IgG isotype by flow cytometry. Based on flow cytometric analysis with multiple strains bearing PspA of clade 1 or 2, we identified $8 \mathrm{mAbs}$ that cross-reacted with at least 6 of the 7 family 1 PspA bearing strains analyzed. These 8 mAbs were further examined for their ability to enhance complement deposition on pneumococci, inhibit lactoferrin-PspA interaction, bacteriocidal and passive protection activity using multiple strains of clade 1 and 2. Our analysis of the antibody response to PspA from R36A demonstrates that the observed crossreactivity and cross-protection is restricted to strains bearing PspA of family 1.

No conflict of interest 


\title{
STREPTOCOCCUS PNEUMONIAE PEP27 MUTANT IS AVIRULENT AND ITS IMMUNIZATION PROVIDES BROAD AND LONG-LASTING PROTECTION
}

\author{
G. Kim¹ ${ }^{1}$, S.Y. Choi ${ }^{2}$, D.E. Briles ${ }^{3}$, S. Pyo², D.K. Rhee ${ }^{2}$ \\ ${ }^{1}$ school of pharmacy, Sungkyunkwan University, Suwon, Korea; ${ }^{2}$ school of pharmacy, Sungkyunkwan University, suwon, Korea; ${ }^{3}$ Depart- \\ ment of microbiology, University of alanama, Birmingham, USA
}

Streptococus pneumoniae causes various invasive diseases. Previously, intranasal immunization of mice with an attenuated autolysis-deficient pep27 mutant induced protective mucosal immunity. In this study, we found that the survival rates of nude and SCID mice after intraperitoneal and intranasal infection with the mutant were similar to R6 non-virulent control indicating that the pep27 mutant is avirulent. The pep27 mutant immunization decreased colonization levels of the serotypes included in commercial vaccines (serotypes 1, 2, 3, 4, 5, 6A, 6B, 8, 19A, 19F, and 23F) as well as serotype 15 and 2 non-typeable strains. To further confirm cross-protection from these heterologous strains, mice immunized with pep 27 mutant were intranasally challenged with serotype $6 \mathrm{~A}, 6 \mathrm{~B}$, or 20 , respectively. The pep27 mutant immunized mice showed significantly higher survival rate than the non-immunized control. Even 3 months post-immunization, which is equivalent to 9 years in human, the levels of IgG and IFN- $\gamma$ in blood and IFN- $\gamma$ in BALF were also significantly higher than those of the non-immunized group. Moreover, when the immunized mice were challenged with D39 3 months post immunization, survival rate was higher than the non-immunized control. Thus, the pep 27 mutant could be a highly feasible mucosal vaccine with broad protection and long-lasting immunity against pneumococcal infections.

No conflict of interest

\section{DEVELOPMENT OF PSPA BASED PNEUMONIA VACCINE SHOWING ENHANCED PROTECTIVE IMMUNITY WHEN CONJUGATED TO VI POLYSACCHARIDE FROM SALMONELLA TYPHI}

N. Kothari ${ }^{1}$, K. Genschmerb ${ }^{2}$

${ }^{1}$ Vaccine Process and Technology Transfer, International Vaccine Institute, Seoul, Korea; ${ }^{2}$ Microbiology, University of Alabama, Alabama, USA

Background and Aims: Phase I data from trials using protein based pneumococcal vaccine antigens show poor immune responses in humans. To address this problem the protein needs to be presented in a way that will induce a stronger antibody response that is more likely to protect humans. We have developed a conjugate vaccine in which PspA, a protein common to all Streptococcus pneumonia was conjugated to Vi capsular polysaccharide from Salmonella typhi. The conjugate significantly increased the antibody response to PspA compared to PspA alone, an antibody response to $\mathrm{Vi}$ was also observed.

Method: We have optimized a scalable high yielding method for fermentation and purification of Vi polysaccharide and of PspA. We have developed and optimized a method for conjugation of PspA to Vi polysaccharide and tested conjugates for their immune response in mice and correlated to the physico-chemical properties of the conjugate. Preliminary challenge studies of $S$. pneumoniae showed protection in vaccinated mice.

Results: A series of Vi-PspA conjugates are prepared and tested in mice. A poor anti-PspA response was obtained when un-conjugated PspA was used as antigen but when conjugated to Vi a substantial increase in the responses were obtained. Mice immunized with a Vi-PspA conjugate showed $70-80 \%$ protection in the preliminary challenge studies done with S. pneumoniae.

Conclusion: The Vi-PspA production and conjugation process was developed for the purpose making a cost effective vaccine which is broadly protective for $S$. pneumoniae serotypes and should also protect against typhoid fever targeting developing countries.

No conflict of interest

ISPPD-0449

Next Generation Vaccines

\section{INTACT STREPTOCOCCUS PNEUMONIAE CELL RECOGNITION BY AFFINITY-PURIFIED ANTIBODIES AGAINST IMMUNODOMINANT B-CELL EPITOPES OF VIRULENT SURFACE PNEUMOCOCCAL PROTEINS (VSPNPS)}

\author{
T. Lagousi ${ }^{1}$, J.G. Routsias ${ }^{2}$, C. Piperi ${ }^{3}$, A. Tsakris² ${ }^{2}$ V. Spoulou ${ }^{1}$, M. Theodoridou ${ }^{1}$ \\ ${ }^{1}$ First Department of Pediatrics “Aghia Sophia” Children's Hospital, University of Athens Medical School, Athens, Greece; ${ }^{2}$ Department of Micro- \\ bilogy, University of Athens Medical School, Athens, Greece; ${ }^{3}$ Department of Biological Chemistry, University of Athens Medical School, Athens, \\ Greece
}

Background and Aims: We have previously identified 10 immunogenic B-cell epitopes within VSPnPs (CbpD, PhtD, PhtE, ZmpB, PspA and PfbB) by screening sera from patients with invasive pneumococcal disease (IPD) against 20mer synthetic peptides (Pep\#1-\#150) covering the entire sequence of antigenic regions. Pep\#4 derived from CbpD, pep\#19 from PhtD and pep\#40 from PhtE were broadly and specifically recognized by IPD patients. This work aimed to evaluate the surface accessibility of these immunodominant epitopes among different pneumococcal serotypes. 
Methods: Antibodies against pep\#4, pep\#19 and pep\#40 (anti-peps) were purified from IPD sera using immunoaffinity columns; immunoblotting against whole cell lysates confirmed their specificity. Intact pneumococcal cells of serotypes 1, 3, 6B, 18C, 19A, 22F and 23B (all clinical isolates) were tested against anti-peps using flow cytometry and immunofluorence microscopy.

Results: Anti-pep\#4, anti-pep\#19 and anti-pep\#40 bound onto the surface of live intact pneumococcal cells. Interestingly, while a 6B isolate was recognized by all anti-peps, another 6B isolate displayed no surface-binding reactivity. Furthermore, structural analysis revealed that pep\#19 and pep\#40 are located within the zinc binding domain of their parent protein.

Conclusion: Specific antibodies against immunodominant B-cell epitopes bound on the surface of different pneumococcal serotypes, encouraging further investigation of their opsonophagocytic function. Two different 6B isolates demonstrated differential surface-binding most likely due to the variation in capsule thickness or in phase variation rates. Anti-pep\#19 and anti-pep\#40 are directed against a functional domain of their parent protein, suggesting that blockade of this protein-zinc interaction interface may neutralize its role as adhesin.

No conflict of interest

\title{
ISPPD-0164
}

Next Generation Vaccines

\section{WHOLE CELL VACCINE-INDUCED TH17 IMMUNOGENICITY AND PROTECTION AGAINST PNEUMOCOCCAL CARRIAGE IS DEPENDENT ON TOLL-LIKE RECEPTOR (TLR)-2 AND DIACYLGLYCERYL TRANSFERASE ENZYME}

\author{
K. Moffitt ${ }^{1}$, A. Howard ${ }^{1}$, S. Martin ${ }^{1}$, M. Herd ${ }^{1}$, Y.J. Lu ${ }^{1}$, A. Basset ${ }^{1}$, R. Malley ${ }^{1}$ \\ ${ }^{1}$ Infectious Diseases, Boston Children's Hospital, Boston, USA
}

Background and Aims: A pneumococcal whole cell vaccine (WCV) confers $\mathrm{T}_{H}$ 17-mediated immunogenicity and reduces nasopharyngeal carriage in mice. Elucidation of underlying immune mechanisms and optimal vaccine characteristics can help guide vaccine development and enhance our understanding of host-pneumococcal interactions. TLR2 activation has been shown to be important for generating $T_{H} 17$ responses; several pneumococcal lipidated proteins have TLR2-activating properties. Thus, we investigated the role of TLR2 and evaluated the requirement of the lipoprotein diacylglyceryl transferase for WCV-induced IL-17A responses and protection against carriage.

Methods: Wild type (WT) or TLR2 ${ }^{-1-}$ C57BL/6 mice were immunized subcutaneously with WCV adsorbed to Alhydrogel ${ }^{\mathrm{TM}}$ (alum) three times two weeks apart. C57BL/6 mice were subcutaneously immunized once with alum and either WCV or WCV from the same pneumococcal strain but with a deletion of lipoprotein diacylglyceryl transferase (WCV $\Delta / g t$ ). Whole blood of immunized animals was stimulated with whole cell antigen and IL-17A was measured from supernatants. Mice were then intranasally challenged with a type 6B Sreptococcus pneumoniae and density of colonization assessed 10 days later.

Results: WCV-immunized TLR2 $\%$ mice had significantly lower IL-17A responses $(p=0.005)$ and significantly higher colonization densities $(p=0.0008)$ compared with WCV-immunized WT mice. Immunization with WCV $\Delta^{\text {lgt }}$ elicited significantly lower IL-17A responses $(p=0.03)$ and was significantly less protective $(p=0.002)$ than WCV.

Conclusion: TLR2 is required for WCV-induced $T_{H} 17$ responses and protection against pneumococcal colonization. Lipidation of proteins may be critical for WCV-generated $\mathrm{T}_{\mathrm{H}} 17$ responses and protective efficacy in a mouse colonization model.

Supported by PATH.

No conflict of interest

ISPPD-0111

Next Generation Vaccines

\section{SAFETY AND IMMUNOGENICITY OF A NEW HEPTAVALENT PNEUMOCOCCAL CONJUGATE VACCINE IN HEALTHY ADULTS. PHASE I.}

B. Paredes-Moreno ${ }^{1}$, N. González-García ${ }^{1}$, S. Pérez-Rodríguez ${ }^{2}$, M. Mirabal ${ }^{3}$, I. Rivero-Vázquez ${ }^{2}$, C.A. González- Delgado $^{2}$, M. Tamayo-Rodríguez ${ }^{2}$, A. Díaz-Machado², M. Martínez-Pérez ${ }^{2}$, J. Rubino-Moreno², R. Oliveros-Oliveros ${ }^{2}$, A. Martín-Trujillo², D. García-Rivera出, L.M. Rodríguez-Noda ${ }^{4}$, A. Pérez-Baños ${ }^{4}$, M.A. Álvarez-García ${ }^{1}$, A. IglesiasMachado $^{1}$, D. Santana-Mederos ${ }^{4}$, Y. Valdés-Balbín ${ }^{4}$, V. Vérez-Bencomo ${ }^{4}$

${ }^{1}$ Clinical Trials, Center for Biomolecular Chemistry, Havana, Cuba; ${ }^{2}$ Clinical Trials, National Center for Toxicology, Havana, Cuba; ${ }^{3}$ Clinical Trials, Finlay Institute, Havana, Cuba; ${ }^{4}$ Immunology, Center for Biomolecular Chemistry, Havana, Cuba

A phase I, parallel, controlled and double blind clinical trial was designed to assess the security in healthy adults of a new conjugate vaccine containing the seven serotypes of Streptococcus pneumoniae more frequently associated with infection in Latina-American. This vaccine (PCV7-TT) has been designed in Cuba, and contains $2 \mu \mathrm{g}$ of each capsular polysaccharide 1,5,14,18C, $19 \mathrm{~F}$ and $23 \mathrm{~F}$ and $4 \mu \mathrm{g}$ of $6 \mathrm{~B}$, conjugated to tetanus toxoid (TT) and aluminum phosphate as adjuvant. Forty subjects were randomized in two groups to receive a dose of PCV7-TT $(n=20)$ or Polysaccharide Vaccine PNEUMO $23^{\circledR}(n=20)$. Each subject was followed for 3 hours after the vaccination for immediate adverse events. During the next 30 days they recorded any adverse events in a diary, and they received medical visits at 7, 21 and 30 days after immunization. Blood samples were obtained before and 30 days after vaccination for immunological evaluation. A dose of PCV7-TT in healthy adults did not report the occurrence of serious adverse events related to the administration of the studied vaccine. The vaccine proved to be as secure as 
a control vaccine capsular polysaccharide 23-valent. The results of the evaluation of antibody concentration and opsonophagocytic titer demonstrated the ability of the vaccine PCV7-TT activated an immune response against the seven vaccinated serotype. This was the first clinical trial with this vaccine, and the results open the way to clinical trial in infants and children.

No conflict of interest

ISPPD-0084

Next Generation Vaccines

\title{
IMMUNOLOGICAL EVALUATION AND PROTECTION EFFICACY OF NEWLY DEVELOPED 13-VALENT PNEUMOCOCCAL CONJUGATE VACCINE IN MICE MODEL
}

C. Park ${ }^{1}$, E.Y. Kwon ${ }^{1}$, J.Y. Park ${ }^{1}$, J.H. Byun ${ }^{1}$, H.S. Chun ${ }^{1}$, S.M. Choi ${ }^{2}$, S.H. Park ${ }^{2}$, J.H. Choi ${ }^{2}$, J.H. Yoo ${ }^{2}$, J.H. Kang ${ }^{3}$, D.G. Lee ${ }^{2}$

${ }^{1}$ Vaccine Bio Research Institute, The Catholic University of Korea College of Medicine, Seoul, Korea; ${ }^{2}$ Department of Internal Medicine, The Catholic University of Korea College of Medicine, Seoul, Korea; ${ }^{3}$ Department of Pediatrics, The Catholic University of Korea College of Medicine, Seoul, Korea

Background and Aims: As pneumococcal disease by non-vaccine-targeted serotypes tends to increase gradually, a 13-valent pneumococcal conjugate vaccine (PCV13) has been developed recently. As encouraged, we evaluated the serological immunity and protection efficacy in mice model of new PCV13 manufactured by a Korean company. Methods: The treatment groups were vaccinated by three different routes: subcutaneously (s.c.), intraperitoneally (i.p.), and intravenously (i.v.), with newly developed PCV13 three times at 2-week intervals. After vaccination, specific antibodie against pneumococcal capsular polysaccharide (PnPs) was measured by enzyme-linked immunosorbent assay (ELISA), and functional IgG was detected by opsonophagocytic killing assay (OPA). Also mice were challenged intraperitoneally with 10 - or 100 -fold of lethal dose $50 \%\left(\mathrm{LD}_{50}\right)$ of Streptoccus pneumoniae strains, and survival was checked for a week.

Results: In PnPs ELISA, end point titer of each serotypes ranged from 1,000 to 6,400. Specific IgG of 3-time vaccination increased more than those of 2 -time vaccination group. S.c. vaccination group produced less 5 - and 23F-specific IgG than those of i.p. or i.m. The endpoint titer of OPA ranged from 16 to 1,280. In the challenge, vaccinated mice showed $100 \%$ of survival rate, while non-vaccinated groups exhibited a fatality rate of $100 \%$. Conclusion: New PCV13 were demonstrated to have the effectiveness of serological immunogenicity and protection efficacy in mice model. These results suggest that newly developed vaccine would provide the possibility of the clinical application, andmice model could be effective in the preclinical trial of PCV13.

No conflict of interest

\author{
ISPPD-0357 \\ Next Generation Vaccines
}

\section{ACCELERATED SCHEDULE OF 10- AND 13-VALENT PNEUMOCOCCAL CONJUGATE VACCINE IS SAFE AND IMMUNOGENIC IN INFANTS IN PAPUA NEW GUINEA}

\author{
W. Pomat ${ }^{1}$, S. Wana ${ }^{1}$, V. Solomon ${ }^{1}$, J. Francis ${ }^{1}$, M. Nenikuro ${ }^{1}$, P. Siba ${ }^{1}$, M. Passey ${ }^{2}$, D. Lehmann ${ }^{3}$, P. Richmond ${ }^{4}$ \\ ${ }^{1}$ Infection and Immunity Unit, Papua New Guinea Institute of Medical Research, Goroka, Papua New Guinea; ${ }^{2}$ University Centre for Rural Health, \\ University of Sydney, Lismore, Australia; ${ }^{3}$ Division of Population Sciences, Telethon Institute for Child Health Research, Perth, Australia; \\ ${ }^{4}$ School of Paediatric and Child Health, University of Western Australia, Perth, Australia
}

Background and Aims: Synflorix (PCV10) and Prevenar13 (PCV13) cover approximately 70-80\% of invasive pneumococcal disease in infants in Papua New Guinea (PNG). We wished to evaluate the safety and immunogenicity of PCV10 and PCV13 when given according to the PNG immunisation schedule.

Methods: 260 infants are being randomised to receive either PCV10 or PCV13 at 1-2-3 months of age in an open randomised controlled trial. Blood is collected pre-vaccination (1 month of age) and at age 4 months ( 1 month postdose 3). Serotype-specific pneumococcal IgG antibodies are measured by the WHO ELISA to PCV13 serotypes and serotype 2.

Results: Interim antibody analysis of 119 children (PCV10 n=62, PCV13 $n=57$ ) showed PCV10 and PCV13 to be immunogenic for the 10 shared vaccine serotypes with $93-100 \%$ and $53-96 \%$ of children achieving IgG concentrations post-dose $3 \geq 0.35 \mu \mathrm{g} / \mathrm{mL}$ and $\geq 1.0 \mu \mathrm{g} / \mathrm{mL}$ respectively. For serotypes, 3, 6A \& 19A IgG levels postdose 3 in PCV13 recipients were $\geq 0.35 \mu \mathrm{g} / \mathrm{mL}$ in $93,93 \%$ \& $100 \%$ and $\geq 1.0 \mu \mathrm{g} / \mathrm{mL}$ in $37 \%, 49 \%$ \& $82 \%$ respectively. For serotype 2 , only $10-18 \%$ of subjects had $\operatorname{lgG} \geq 1 \mu \mathrm{g} / \mathrm{mL}$ at 4 months. PCV13 GMTs were significantly higher postdose3 than in PCV10 recipients for serotype 6B $(p=0.02)$ and 19F $(p=0.001)$ as well as non-PCV10 serotypes 3, 6A $\& 19 A(p<0.001)$.

Conclusion: As the first study to directly compare immunogenicity of PCV10 and PCV13 when given at 1-2-3 month, the vaccines are immunogenic in PNG infants with PCV13 offering additional serotype coverage. The ongoing study will also examine the role of pneumococcal polysaccharide vaccine as a booster at 9 months of age to provide additional protection.

No conflict of interest 
ISPPD-0169

Next Generation Vaccines IMMUNOGENICITY AND SAFETY OF 11- AND 12-VALENT PNEUMOCOCCAL NON-TYPEABLE HAEMOPHILUS
INFLUENZAE PROTEIN D-CONJUGATE VACCINES (11VPHID-CV, 12VPHID-CV) IN INFANTS: PHASE-II STUDY

A. Carmona Martinez ${ }^{1}$, R. Prymula ${ }^{2}$, M. Miranda Valdivieso ${ }^{3}$, C. Otero Reigada ${ }^{4}$, J. Diez-Delgado ${ }^{5}$, J.M. Merino ${ }^{6}$, J. Brzostek $^{7}$, L. Szenborn ${ }^{8}$, R. Ruzkova ${ }^{9}$, M. Horn ${ }^{10}$, T. Jackowska ${ }^{11}$, F. Centeno Malfaz ${ }^{12}$, M. Traskine ${ }^{13}$, K. Dobbelaere ${ }^{13}$, D. Borys ${ }^{13}$

${ }^{1}$ Instituto Hispalense de Pediatría Spain, Sevilla, Spain; ${ }^{2}$ Directorate, University Hospital Hradec Králové and Medical Faculty Charles University, Hradec Králové, Czech Republic; ${ }^{3}$ Hospital de Antequera, Malaga, Spain; ${ }^{4}$ La Fe Hospital, Valencia, Spain; ${ }^{5}$ UGC de Pediatría, Hospital Torrecárdenas, Almeria, Spain; ${ }^{6}$ Pediatric Department, Hospital General Yagüe, Burgos, Spain; ${ }^{7}$ Health Care Establishment in Debica Infectious Diseases Outpatient Clinic, Debica, Poland; ${ }^{8}$ Medical University Wroclaw, Wroclaw, Poland; ${ }^{9}$ Pediatric Office Dr. Renata Ruzkova, Prague, Czech Republic; ${ }^{10}$ Pediatric Office Dr. med. Michael Horn, Berchtesgaden, Germany; ${ }^{11}$ Department of Pediatrics, Medical Center of Postgraduate Education, Warsaw, Poland; ${ }^{12}$ Department of Pediatrics, Rio Hortega University Hospital, Valladolid, Spain; ${ }^{13}$ Vaccine Discovery and Development, GlaxoSmithKline Vaccines, Wavre, Belgium

Background and Aims: We evaluated the immunogenicity and safety of investigational 11vPHiD-CV and 12vPHiD-CV, containing 19A-CRM ${ }_{197}$ (11vPHiD-CV and 12vPHiD-CV) and 6A-CRM ${ }_{197}$ (12vPHiD-CV only) conjugates in addition to the 10 serotype-specific conjugates in the licensed 10-valent vaccine (PHiD-CV, GlaxoSmithKline Vaccines).

Methods: In this phase II, partially-blinded study (NCT01616459) in Europe, healthy infants were randomized (1:1:1:1) to receive primary and booster vaccination (at 2/3/4/12-15 months of age) with 11vPHiD-CV, 12vPHiDCV, PHiD-CV or 13-valent pneumococcal $\mathrm{CRM}_{197}$-conjugate vaccine (13vCRM, Wyeth LLC), coadministered with DTPa-HBV-IPV/Hib. First co-primary objective: to demonstrate immunological non-inferiority of $11 \mathrm{vPHiD-CV}$ versus 13vCRM (for 19A) or PHiD-CV (for 10 PHiD-CV serotypes) for $\geq 9$ out of 11 serotypes, after primary vaccination. Second sequential co-primary objective: to demonstrate immunological non-inferiority of 12vPHiD-CV versus 13vCRM (for 19A, 6A) or PHiD-CV (for 10 PHiD-CV serotypes) for $\geq 10$ out of 12 serotypes, after primary vaccination. Solicited and unsolicited symptoms were recorded for 4 and 31 days post-vaccination, respectively; serious adverse events throughout the study.

Results: Both co-primary objectives were met. Post-primary immune responses are shown in the table. The safety and reactogenicity profiles of $11 \mathrm{vPHiD}-\mathrm{CV}$ and $12 \mathrm{vPHiD}-\mathrm{CV}$ were in line with that of PHiD-CV.

Conclusion: 11vPHiD-CV and 12vPHiD-CV given to infants as 3-dose primary vaccination were immunogenic and well-tolerated. The $6 \mathrm{~A}$ and $19 \mathrm{~A}$ conjugates did not appear to negatively affect immunogenicity of the other 10 conjugates or protein $D$.

Funding: GlaxoSmithKline Biologicals SA

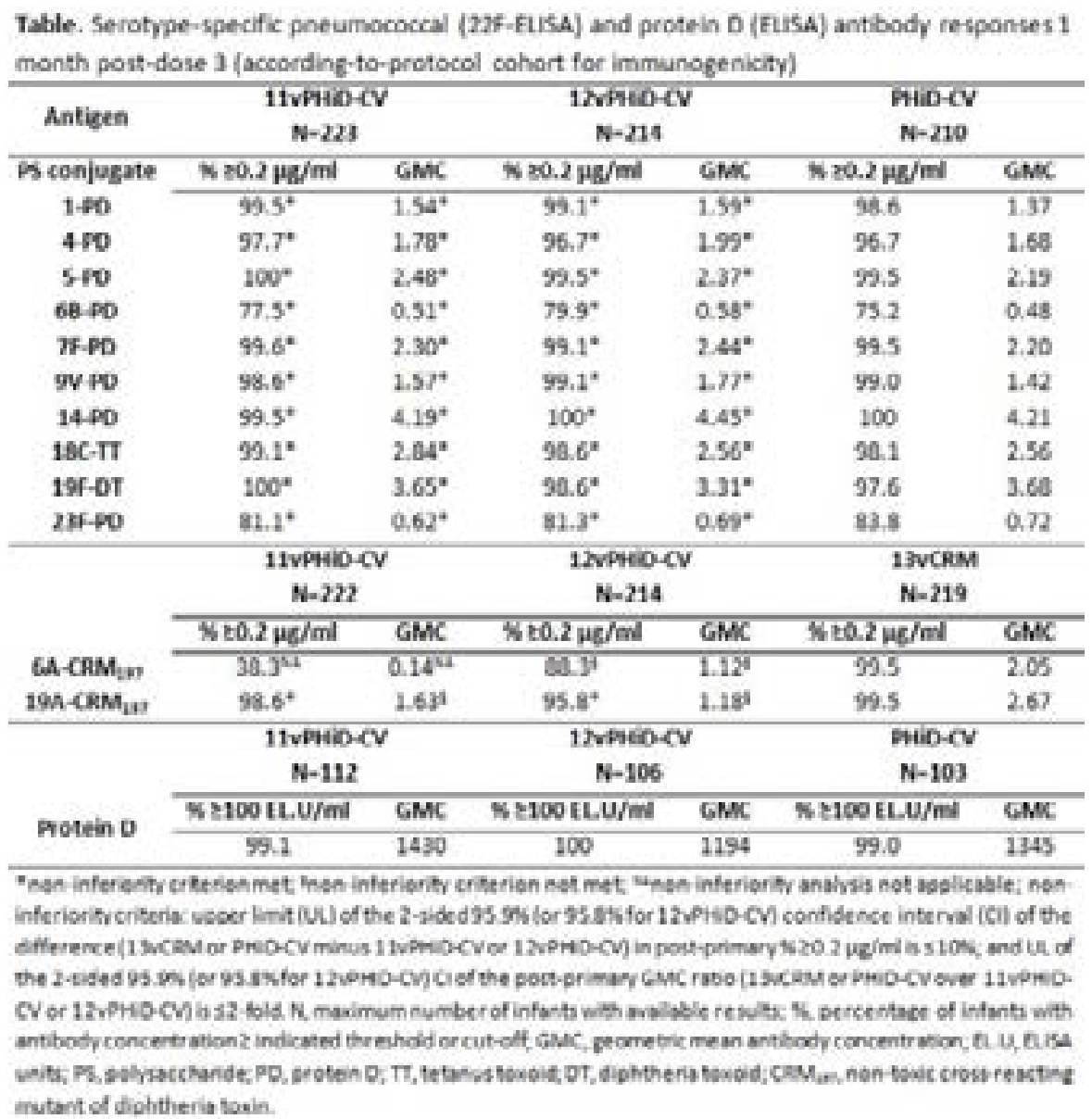




\section{SAFETY AND REACTOGENICITY OF 2 FORMULATIONS OF AN INVESTIGATIONAL PROTEIN-BASED PNEUMOCOCCAL VACCINE IN INFANTS IN EUROPE: A PHASE II TRIAL}

R. Prymula ${ }^{1}$, L. Szenborn ${ }^{2}$, S.A. Silfverdal ${ }^{3}$, J. Wysocki ${ }^{4}$, P. Albrecht ${ }^{5}$, N. François 6 , A. Gardev ${ }^{6}$, D. Borys ${ }^{6}$ ${ }^{1}$ Directorate, University Hospital Hradec Králové and Medical Faculty Charles University, Hradec Králové, Czech Republic

${ }^{2}$ Medical University Wroclaw, Wroclaw, Poland; ${ }^{3}$ Umeå University, Umeå, Sweden; ${ }^{4}$ University School of Medical Sciences \& Regional Medical Center for Mother and Child, Poznan, Poland; ${ }^{5}$ Medical University of Warsaw, Warsaw, Poland; ${ }^{6}$ GlaxoSmithKline Vaccines, Wavre, Belgium

Background and Aims: Safety and reactogenicity of 2 formulations of an investigational protein-based pneumococcal vaccine were evaluated in infants in 4 European countries.

Methods: In this phase II, multicenter, observer-blind study (NCT01204658), healthy 6-14-week-old infants were randomized (1:1:1:1) to receive 3-dose primary and booster vaccination (at 2, 3, 4, 12-15 months of age) with 10 -valent pneumococcal non-typeable Haemophilus influenzae protein D conjugate vaccine (PHiD-CV) combined with pneumolysin toxoid (dPly) and histidine triad protein D (PhtD), each at either $10 \mu \mathrm{g}$ (PHiD-CV/dPly/PhtD-10) or $30 \mu \mathrm{g}$ (PHiD-CV/dPly/PhtD-30), PHiD-CV (GlaxoSmithKline Vaccines) or the 13-valent pneumococcal CRM conjugated vaccine (13vCRM, Wyeth LLC). All vaccines were co-administered with DTPa-HBV-IPV/Hib. Solicited and unsolicited adverse events (AEs) were recorded within 7 and 31 days post-vaccination, respectively; serious AEs (SAEs) throughout the study. We present results until 1 month post-primary vaccination. First and second (sequential) primary objectives were to demonstrate non-inferiority of PHiD-CV/dPly/PhtD-10 and PHiD-CV/dPly/ PhtD-30 versus PHiD-CV in terms of post-primary vaccination-related fever $>40.0^{\circ} \mathrm{C}$.

Results: Among the 575 vaccinated infants, no fever $>40.0^{\circ} \mathrm{C}$ was reported; both primary objectives were met. Table 1 summarizes the occurrence of AEs. The most frequently reported unsolicited AEs were respiratory tract infections. 1 SAE (hypotonic hyporesponsive episode) was considered as vaccination-related. No fatal SAEs were reported. Conclusion: The 2 protein-based pneumococcal vaccine formulations had a safety profile in line with that of PHiDCV in infants.

Funding: GlaxoSmithKline Biologicals SA

Table 1. Persentages of overall vaseine doses followed by solicited and unsolicited adverse events (AEs) and percentages of participants with at least 1 serious $\Delta E$ (SAE) (total vactinated cohort)

\begin{tabular}{|c|c|c|c|c|}
\hline & $\begin{array}{c}\text { DHio. N/dPly/phen. 10 } \\
\begin{array}{c}\text { Nuse/434 } \\
N *-146\end{array}\end{array}$ & 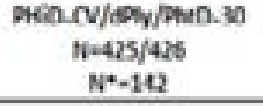 & $\begin{array}{l}\text { Ptin.CV } \\
N=431 / 432 \\
N *-145\end{array}$ & $\begin{array}{c}13 \mathrm{MCRM} \\
N=426 / 426 \\
N^{*}-12\end{array}$ \\
\hline \multicolumn{5}{|c|}{ Ioral solíited Afs } \\
\hline $\begin{array}{l}\text { Pain } \\
\text { Grade } 3\end{array}$ & $\begin{array}{c}33.1(28.7-37.7) \\
0.9(0.2-2.3)\end{array}$ & $\begin{array}{c}50.6(20.2-53.2) \\
1.2(0.4-2.7)\end{array}$ & $\begin{array}{c}30.6(263-55.2) \\
1.2(0.4-2.7)\end{array}$ & $\begin{array}{c}90.0(25.7-94.6) \\
0.7(0.1-20)\end{array}$ \\
\hline $\begin{array}{l}\text { Reurews } \\
230 \mathrm{~mm}\end{array}$ & $\begin{array}{c}43.6(38.5-48.4) \\
1.1(0.4-2.6)\end{array}$ & $\begin{array}{c}4.7(39.5-43.6) \\
0.9(0.3-2.4)\end{array}$ & $\begin{array}{c}40.1(35.5-44.9) \\
1.4(0.5-3.0)\end{array}$ & $\begin{array}{c}41.1(26.4-45.9\} \\
1.2(0.4-27\}\end{array}$ \\
\hline $\begin{array}{l}\text { Swtare } \\
730 \mathrm{~mm}\end{array}$ & $\begin{array}{c}53.8 \text { \{29.4-38.4\} } \\
3.2(1.8 .5 .3)\end{array}$ & $\begin{array}{l}5.2[31.1-41.0) \\
2.8(1.5 .49)\end{array}$ & $\begin{array}{c}218(23)(-32.3) \\
29(0.8-3.6)\end{array}$ & $\begin{array}{c}21.1(255-92.2) \\
3.3(1.8-5.5)\end{array}$ \\
\hline \multicolumn{5}{|c|}{ Generdal solicited AIs } \\
\hline $\begin{array}{l}\text { Pever" } \\
240.00 \mathrm{C}\end{array}$ & $\begin{array}{c}25.8(21.0-30.2) \\
0.0(0.0-6.5)\end{array}$ & $\begin{array}{c}24.7(20.7-23.1) \\
0.0(0.0-0.9)\end{array}$ & $\begin{array}{c}27.4(23.2-51.8) \\
0.0(0.0-0.9)\end{array}$ & $\begin{array}{c}22.5(18.7-26.8) \\
0.0(0.0 .09)\end{array}$ \\
\hline intrabilty & $55.5(30.7-60.2)$ & $55.5(50.7-60.3)$ & $550(30.2-59.8)$ & $56.6(51.7-51.3)$ \\
\hline Grade 3 & $48(3.0-7.2)$ & $3.1(1.6-5.2)$ & $2.9(2.3-6.2)$ & $2.1(1.6-5.2)$ \\
\hline Crowsiness & $47.9(43.2-527]$ & 4.. $(39.2-48.9)$ & $45.9(41 ;-30.8)$ & $4.8(60.0-49.7)$ \\
\hline Crade 3 & $2.3(1.14 .2)$ & $0.5(0.1-17)$ & $0.9(0.3 \cdot 2.4)$ & $0.9\{0.3 .2 .4\}$ \\
\hline Less of apoetite & $224(28.6-26.6)$ & $20.5(16.7-246)$ & $22.1(17.4-25.3)$ & 19.5 (17.5. $5-23.6)$ \\
\hline Grade 2 & $0.2(0.0-13)$ & $0.7(0.1-2.0)$ & $0.5(0.1-1.7)$ & $0.5(0.1-1.7)$ \\
\hline Unsolicited Afr & $169(135-207)$ & $21.1(17.3-25.3)$ & $20.1(16.5-24.2)$ & 19.7 (15.0-23.8) \\
\hline Srade 3 & $0.0(0.0-0.8)$ & $0.2(0.0-1.3)$ & $0.5(0.1-1.7)$ & $0.2(0.0-13)$ \\
\hline SNs & 1.4 & 1.4 & 6.9 & 2.1 \\
\hline
\end{tabular}

Conflict of interest 
ISPPD-0193

Next Generation Vaccines

\section{PHASE I CLINICAL TRIAL IN CHILDREN WITH A CUBAN HEPTAVALENT PNEUMOCOCCAL CONJUGATE VACCINE}

R. Puga-Gomez ${ }^{1}$, C.P. Dotres-Martínez ${ }^{1}$, C.R. Broño ${ }^{2}$, C.R. Ruiz², Y. Ricardo ${ }^{1}$, B. Paredes-Moreno ${ }^{3}$, N. González-García ${ }^{3}$, S. Rosell-León ${ }^{3}$, Y. García-Cristia ${ }^{1}$, R.A. del Valle-Rodríguez ${ }^{1}$, V. Echemendía-Marín ${ }^{3}$, J.L. Lam-Hernández ${ }^{1}$, T. Orta-Pi$\mathrm{no}^{2}$, B. Betancourt-Pérez ${ }^{2}$, M.E. Mesa-Herrera ${ }^{1}$, A. Rodríguez-Concepción ${ }^{2}$, D. Duany-Álvarez ${ }^{1}$, D. Santana-Mederos ${ }^{4}$, Y. Valdés-Balbín ${ }^{4}, \mathrm{~V}$. Vérez-Bencomo ${ }^{4}$

${ }^{1}$ Pediatrics-Immunology, Pediatric Hospital "Juan Manuel Marquez"., Havana, Cuba; ${ }^{2}$ Primary Health Care, Primary Health System from Marianao., Havana, Cuba; ${ }^{3}$ Clinical Trials, Center for Biomolecular Chemistry, Havana, Cuba; ${ }^{4}$ Immunology, Center for Biomolecular Chemistry, Havana, Cuba

A new conjugate vaccine containing the seven serotypes of Streptococcus pneumoniae more frequently associated with infection in Latinamerican have been designed in Cuba. The candidate vaccine (PCV7-TT) contains $2 \mu \mathrm{g}$ of each capsular polysaccharide $1,5,14,18 \mathrm{C}, 19 \mathrm{~F}$ and $23 \mathrm{~F}$ and $4 \mu \mathrm{g}$ of $6 \mathrm{~B}$, conjugated to tetanus toxoid (TT) and aluminum phosphate as adjuvant. The safety of the vaccine in healthy adults was showed during 2012 . Then, the Cuban National Regulatory Authority recommended assessing the safety in children around 5 years old, previous to clinical trials in infants. A phase I, parallel, controlled and double blind clinical trial was designed to assess the safety of PCV7 in fifteen 4-5 years old children. The protocol was reviewed by the Ethics Committee of "Juan Manuel Márquez" Pediatric Hospital. Children were randomized to received one dose of PCV7-TT ( $n=10)$ or Synflorix $(n=5)$. Each child was followed for 3 hours after the vaccination for immediate adverse events. During the next 30 days the child's parents recorded any adverse events in a diary, and they received medical visits at 7, 21 and 30 days after immunization. Blood samples were obtained before and 30 days after vaccination for immunological evaluation. No serious adverse events were reported using PCV7-TT. The adverse events reported were comparable between both vaccines, and local pain was the most frequent. PCV7-TT shows a good safety profile. Once demonstrate the general safety profile of PCV7-TT in children, we started Phase I clinical trials in infant during last semester 2013.

No conflict of interest

ISPPD-0063

Next Generation Vaccines

\section{PRECLINICAL DEVELOPMENT OF THE NANOPARTICLE PLATFORM FOR A BROADLY MULTIVALENT PNEUMOCOCCAL VACCINE}

M. Stone ${ }^{1}$, S. Rele ${ }^{1}$, R. Robeson ${ }^{1}$, A. Beletskii ${ }^{1}$, J. Hansen ${ }^{1}$, M. Earl ${ }^{1}$, G. Fawcett ${ }^{1}$, M. Lily ${ }^{1}$, J. Marchand ${ }^{1}$, M. Stone $^{1}$, C. Bernasconi ${ }^{1}$, R. Yadavalli ${ }^{1}$, J. Conley ${ }^{1}$, N. Meyer ${ }^{1}$, L. Kelly ${ }^{1}$, M. Hunter ${ }^{1}$, F. Malinoski $^{1}$, B. Yerxa ${ }^{1}$, J. Maisonneuve ${ }^{2}$, M. Alderson ${ }^{2}$

${ }^{1}$ Polysaccharide Protein Vaccines, LIQUIDIA TECHNOLOGIES, Durham, USA; ${ }^{2}$ Pneumococcal Vaccines, Path, Seattle, USA

Background and Aims: New generation ${ }^{\circledR}$ PRINT nanoparticle Pneumococcal vaccine aims to harness key pathogen associated molecular features that can be mimicked for B/T-cell targeting to induce potent antigen-specific immune responses. ${ }^{\circledR}$ PRINT nanoparticles with defined antigenic compositions have been characterized extensively by physicochemical and bioanalytical assays for quantifying the polysaccharide (all Prevnar 13 serotypes) and protein $\left(\mathrm{CRM}_{197}, \mathrm{PLD}\right)$. The impact of particle shape and size $(200 \times 200 \mathrm{~nm}, 80 \times 320 \mathrm{~nm}, 1 \mathrm{~m}$ cylinder, 1X3m disc) on immunogenicity in BALB/c mice was studied. Downstream purification of ${ }^{\circledR}$ PRINT nanoparticle suspensions was evaluated by Tangential flow filtration (TFF).

Methods: In vitro antibody-based ELISA, DIONEX and bicinchoninic acid (BCA) assays have been developed to quantify the amount of polysaccharide and protein in ${ }^{\circledR}$ PRINT nanoparticle formulations. Antigen-specific IgG (all 13 strains) and cellular assays (IL-17, IFN- $\gamma$ ) for 3 serotypes to quantitate the immune response have been adapted to mice. ${ }^{\circledR}$ PRINT particles were manufactured using roll-to-roll ${ }^{\circledR}$ PRINT manufacturing process for PnPs1, 5, 14 and were purified by evaluating TFF process parameters (membrane pore size, MWCO membrane, pressure, buffers). Results: All Prevnar 13 serotypes can be formulated and quantified into ${ }^{\circledR}$ PRINT particles. Antigen-specific IgG (all 13 strains) and cellular assays (IL-17, IFN- $\gamma$ ) on 3 serotypes have been adapted to mice and quantitated to measure antibody and cytokine responses. Smaller and sterile filterable ${ }^{\circledR}$ PRINT PnPs14 particles induced robust IgG responses that are $\sim 3$-fold better than larger particles. TFF of ${ }^{\circledR}$ PRINT suspensions afforded stable nanoparticle formulations with average particle size of $\sim 250 \mathrm{~nm}$ and $>70 \%$ post TFF recovery yield.

Conclusion: Incorporation of all of the Prevnar 13 polysaccharides and multiple proteins as carriers in ${ }^{\circledR P R I N T}$ formulations has demonstrated that a wide-ranging multi-antigen formulation that could allow for broadened efficacy.

No conflict of interest 
ISPPD-0062

Next Generation Vaccines

\section{NONADJUVANTED CODELIVERY OF ANTIGENS USING NANOPARTICLE PNEUMOCOCCAL VACCINE: EFFECTIVE ANTIGEN PRESENTATION AND DELIVERY FOR ENHANCED IMMUNOGENICITY}

S. Rele ${ }^{1}$, A. Beletskii ${ }^{1}$, C. Bernasconi ${ }^{1}$, J. Conley ${ }^{1}$, M. Earl ${ }^{1}$, G. Fawcett ${ }^{1}$, J. Hansen ${ }^{1}$, L. Kelly ${ }^{1}$, M. Lily ${ }^{1}$, F. Malinoski ${ }^{1}$, J. Marchand ${ }^{1}$, N. Meyer ${ }^{1}$, S. Rele ${ }^{1}$, R. Robeson $^{1}$, M. Stone ${ }^{1}$, R. Yadavalli ${ }^{1}$, B. Yerxa ${ }^{1}$, J. Maisonneuve ${ }^{2}$, M. Alderson ${ }^{2}$

${ }^{1}$ Polysaccharide Protein Vaccines, LIQUIDIA TECHNOLOGIES, Durham, USA; ${ }^{2}$ Pneumococcal Vaccines, Path, Seattle, USA

Background, Aims: ${ }^{\circledR}$ PRINT nanoparticle system is designed to imitate size and structural aspects of bacterial pathogens for the most efficient presentation and delivery of polysaccharide and protein antigens to elicit maximum immune responses. We have constructed defined ${ }^{\circledR} \mathrm{PRINT}$ nanoparticle formulations of $\mathrm{CRM}_{197}$ and mutant pneumolysin protein (PLD) as carrier protein/immunogen with pneumococcal polysaccharides (PnPs) 1, 5, 14, using ${ }^{\circledR}$ PRINT nanoparticle system.

Methods: Preclinical immunization studies in BALB/c mice ( $n=6 /$ group) were conducted to evaluate antibody (IgG) responses to the ${ }^{\circledR}$ PRINT vaccine candidates. Specifically, mice were vaccinated three times subcutaneously with various ${ }^{\circledR}$ PRINT formulations with defined compositions. Immunogenicity endpoints included antigen-specific (serotype/protein) IgG levels and opsophagocytic killing assay calibrated against Prevnar 13 responses.

Results: Nonadjuvated ${ }^{\circledR}$ PRINT particles elicited statistically robust anti-PnPs1, 5, 14 antibody responses to both $\mathrm{CRM}_{197}$ and PLD carrier protein ( $\geq$ Prevnar 13 ). ${ }^{\circledR} \mathrm{PRINT}$ formulations show consistently strong correlations between serotype specific IgG titers and functional opsonophagocytic killing (OPK) responses. Depending on the formulation, strong anti-PLD immune responses were generated when compared to soluble PLD. Significantly, we have also demonstrated the ability of PLD not only to serve as an alternative carrier protein to CRM $_{197}$ but also act as an effective immunogen in ${ }^{\circledR}$ PRINT formulations.

Conclusions: Effective co-delivery of the polysaccharide and carrier protein together as components of ${ }^{\circledR P R I N T}$ particles induces enhanced immunogenicity. Significantly, PLD as a carrier protein can also act as an effective immunogen when presented along with polysaccharides in ${ }^{\circledR}$ PRINT particles. ${ }^{\circledR}$ PRINT nanoparticle formulations hold potential for a low cost and simplified manufacturing path for multivalent particulated pneumoccocal vaccines.

No conflict of interest

ISPPD-0545

Next Generation Vaccines

\section{CONSERVED SURFACE ACCESSIBLE STREPTOCOCCUS PNEUMONIAE PROTEIN SP_0845 ELICITS OPSONIC ANTIBODIES AND IS PROTECTIVE IN VIVO}

S. Saxena ${ }^{1}$, N. Khan ${ }^{1}$, D. Sehgal ${ }^{1}$

${ }^{1}$ Molecular Immunology Laboratory, National Institute of Immunology, NEW DELHI, India

Streptococcus pneumoniae is a leading cause of bacterial pneumonia, meningitis and sepsis. Surface accessible proteins of $S$. pneumoniae are being explored for the development of a protein-based vaccine in order to overcome the limitations of existing polysaccharide-based pneumococcal vaccines. To identify potential vaccine candidates, we resolved surface-associated proteins of S. pneumoniae TIGR4 strain using two-dimensional gel electrophoresis followed by immunoblotting with antisera generated against whole heat-killed TIGR4. Ten immunoreactive spots were identified by mass spectrometric analysis that included a putative lipoprotein SP_0845. Analysis of the inferred amino acid sequence of SP 0845 homologues from 36 diverse pneumococcal strains indicated that SP_0845 was highly conserved ( $>98 \%$ identity) and showed less than $11 \%$ identity with any human protein. Our data suggested that SP_0845 occurs as 8 distinct alleles with allele 4 being the most common allele with a frequency of $55.5 \%$. Immunoblot analysis suggested that SP_0845 is expressed in in vitro grown pneumococci and during mice infection. Immunofluorescence microscopy and flow cytometry data indicated that SP 0845 was surface exposed and accessible to antibodies in the 4 encapsulated strains analyzed. Subcutaneous immunization with purified recombinant SP 0845 induced high titer antibodies in mice. Anti-SP 0845 sera promoted killing of 4 encapsulated pneumococcal strains as assessed by blood bactericidal assay. Immunization with recombinant SP_0845 protected mice when challenged intraperitoneally with heterologous pneumococcal serotypes. Based on the accessibility to antibodies and its ability to elicit protective immunity, we propose that SP_0845 may be a promising candidate for inclusion in a future multi-component protein-based pneumococcal vaccine.

No conflict of interest 


\title{
MACROPHAGES PLAY A KEY ROLE IN THE PROTECTION BY STREPTOCOCCUS PNEUMONIAE PEP27 MUTANT VACCINE
}

\author{
S.H. Seon ${ }^{1}$, S.Y. Choi $^{1}$, D.E. Briles ${ }^{2}$, S.N. Pyo ${ }^{1}$, D.K. Rhee ${ }^{1}$ \\ ${ }^{1}$ School of Pharmacy, Sungkyunkwan University, Suwon, Korea; ${ }^{2}$ Department of Microbiology, University of Alabama at Birmingham, Birming- \\ ham, USA
}

Streptococcus pneumoniae is responsible for high mortality, causing various invasive pneumococcal diseases. Since several problems such as serotype shifts have been found despite introduction of current pneumococcal vaccine, a new type of vaccine is needed to solve these problems. Previously, intranasal immunization of the pep27 mutant showed protection against heterologous lethal challenge indicating that the mutant could be a highly feasible vaccine candidate. To elucidate the underlying mechanism of the protection, humoral and cellular responses in immunized and non-immunized groups were compared. Although the level of IgG in the immunized group was significantly increased, there was no passive-immunity against lethal D39 challenge. Moreover, when CD4+ and CD8+ T cells were depleted from the immunized mice followed by lethal challenge, the mice did not show mortality whereas non-immunized group did indicating that T cells may not be involved in the protection. However, BALF from the immunized mice showed significantly higher level of IFN- $\gamma$ when exposed to D39, indicating the involvement of IFN- $\gamma$-activated macrophages. In in vitro study, phagocytic activities of bone marrow-derived macrophages from the immunized mice were significantly increased when exposed to D39 compared to non-immunized group. In addition, flow cytometric assay showed spleen-derived monocytes from the immunized mice differentiated much rapidly into macrophages than those from the non-immunized group. Overall, these results suggested that IFN- $\gamma$ activated macrophages, but not T and B cells, could be important for the protection from lethal infection after i.n. immunization with the pep27 mutant.

No conflict of interest

ISPPD-0210

Next Generation Vaccines

\section{PUBLIC HEALTH IMPORTANCE AND IMMUNOLOGICAL BENEFIT OF INCLUSION OF SEROTYPES 22F AND 33F IN A NEXT GENERATION PNEUMOCOCCAL CONJUGATE VACCINE}

J. Skinner ${ }^{1}$, L. Indrawati ${ }^{1}$, I. Caro-Aguilar ${ }^{1}$, W. Smith², D. Nawrocki², J. Blue ${ }^{2}$, M. Winters ${ }^{2}$, J. MacNair ${ }^{2}$, Y. Cui ${ }^{3}$, Y. Zhang ${ }^{4}$, J. Antonello ${ }^{4}$, N. Pujar ${ }^{2}$, J. Heinrichs ${ }^{1}$

${ }^{1}$ Vaccines Research, Merck, West Point, USA; ${ }^{2}$ Bioprocess Research \& Development, Merck, West Point, USA; ${ }^{3}$ Epidemiology, Merck, West Point, USA; ${ }^{4}$ Non-clinical Statistics, Merck, West Point, USA

Pneumococcal-polysaccharide-conjugate vaccines (PCV) have had a major impact on the reduction of pneumococcal disease. However, since the introduction of PCVs, there has been a compensatory increase in the prevalence of certain serotypes not contained in the licensed vaccines, including, most recently, serotypes $22 \mathrm{~F}$ and 33F. Therefore, we have developed a 15-valent pneumococcal conjugate vaccine (PCV-15) which includes polysaccharides (PS) 22F and 33F, in addition to the PCV13 serotypes $(1,3,4,5,6 \mathrm{~A}, 6 \mathrm{~B}, 7 \mathrm{~F}, 9 \mathrm{~V}, 14,18 \mathrm{C}, 19 \mathrm{~A}$, $19 \mathrm{~F}$, and 23F). All polysaccharides are conjugated to $\mathrm{CRM}_{197}$ and formulated with an aluminum phosphate adjuvant. Immunogenicity of PCV-15 was evaluated in infant rhesus monkeys (IRM) and adult New Zealand white rabbits (NZWR) using multiarray electrochemiluminescence (ECL) assays to measure serotype-specific IgG antibodies and opsonophagocytic killing assays (OPA) to measure functional antibody responses. In IRMs, results indicated that serotype $22 \mathrm{~F}$ and $33 \mathrm{~F}$ conjugates had 3 and $0.87 \mu \mathrm{g} / \mathrm{ml}$ post-dose 3 antibody responses, respectively, based on the sp007 reference standard. NZWRs immunized with PCV-15 had post-dose 2 geometric mean titers 11 and 14-fold higher than baseline for $22 \mathrm{~F}$ and $33 \mathrm{~F}$, respectively. Testing for OPA functional antibody activity against both serotypes 22F and 33F showed titers of 1:256 in IRMs and 1:512 and 1:1024 in NZWRs, respectively. These results demonstrate that serotypes $22 \mathrm{~F}$ and $33 \mathrm{~F}$ are immunogenic and produce functional antibody responses in preclinical animal models. These additional serotypes in expanded PCVs may be beneficial, as they are becoming more prominent causes of IPD and inclusion in a PCV may offer additional protection.

Conflict of interest 


\title{
IMMUNIZATION WITH GENETICALLY FUSED SP2108, SP1912 AND SP0148 PROTEINS PRIMES TH17 RESPONSES THAT ARE PROTECTIVE IN A MOUSE COLONIZATION MODEL
}

M. Skoberne ${ }^{1}$, K. Moffitt $^{2}$, C. Gavrilescu ${ }^{1}$, B. Dixit ${ }^{1}$, S. Munzer $^{1}$, P. Gouveia ${ }^{1}$, S. Pluskey ${ }^{1}$, N. Siddall ${ }^{1}$, D. Turkington $^{1}$, P. Giannasca ${ }^{1}$, M. Alderson ${ }^{3}$, R. Malley ${ }^{2}$, J. Flechtner ${ }^{1}$

${ }^{1}$ Genocea Biosciences, Cambridge, USA; ${ }^{2}$ Boston Children's Hospital, Boston, USA; ${ }^{3}$ Path, Seattle, USA

Background: Prevention of nasopharyngeal colonization is important in eradication of Stretococcus pneumoniaemediated disease. We identified three conserved protein antigens recognized by $T_{H} 17$ cells from healthy humans. SP2108 and SP0148 are both lipidated, membrane transport-associated proteins, and SP1912 is a non-lipidated putative protein. When adsorbed to Alhydroge ${ }^{\circledR}$ and administered subcutaneously to mice, these antigens elicit $\mathrm{T}_{\mathrm{H}} 17 \mathrm{~T}$ cell responses and significantly decrease colonization of the nasopharynx via a TLR2-dependent mechanism. Aim: Our goal was to create a cost-effective pneumococcal vaccine by combining multiple antigens into a single fusion construct, while preserving the immunogenicity and efficacy of the individual antigens.

Methods: Fusion proteins consisting of an N-terminal lipoprotein followed by one or two non-lipidated antigens were produced, evaluated in vitro for TLR2 activation, and assessed as vaccines in C57BL/6 mice. Mice were immunized with fusion proteins adsorbed to Alhydroge ${ }^{\circledR}$, systemic $T_{H} 17$ responses measured, and were intranasally challenged with type 6B pneumococci. Colonization density was assessed 10 days later.

Results: Fusion proteins triggered comparable TLR2 responses to non-fused lipidated proteins in vitro. The fusions were immunogenic over a range of doses $(30-300 \mathrm{pmol})$, consistent with the individual antigens. Three of eight fusions, GB154, GB155 and GB162, were prioritized based on statistically significant reduction in colonization of up to 1.9 logs (range 1.3-1.9) compared to the Alhydroge ${ }^{\circledR}$-immunized animals. The results were comparable to the combination of the three individual antigens.

Conclusion: Multiple protein antigens can be fused to create an effective parenteral vaccine designed to induce $\mathrm{T}_{\mathrm{H}} 17$ responses that protect against pneumococcal carriage.

Conflict of interest

ISPPD-0367

Next Generation Vaccines

\section{ANALYZING PNEUMOCOCCAL SURFACE PROTEIN A (PsPA) VARIABILITY FOR PREDICTING CONSERVED T CELL EPITOPES AND DESIGNING CONSERVED EPITOPE BASED DNA VACCINE}

\author{
P.S. Slathia ${ }^{1}$, P. Sharma ${ }^{1}$ \\ ${ }^{1}$ Biotechnology, Shri Mata Vaishno Devi University, Jammu, India
}

Background and Aims: Pneumococcal surface protein A (PspA) is highly immunogenic and has elicited protective immunity against Streptococcus pneumoniae in mice. PspA has been found in all the clinical isolates till date. However, the protein has numerous variants which makes it challenging to design vaccines. We have tried to study all the variants available in the National Center for Biotechnology Information protein database for finding the conserved epitopes.

Methods: The retrieved protein sequences were aligned by ClustalW. The aligned sequences were divided into small clusters of 10-15 sequences for further analysis. The conserved sequences greater than 9 amino acid residues in length were used for Class I MHC binding predictions. Similarly sequences greater than 15 amino acid residues were used to predict Class IIMHC binders. NetMHCPan, NetMHCIIPan, IEDB analysis were used for predictions. Epitopes after analysis for parameters like self epitope removal, allergen prediction etc. were tandemly joined to obtain two peptide sequences- one comprising of $\mathrm{MHC}$ I binders and second of $\mathrm{MHC}$ II binders. After reverse translation using human codon usage table these DNA sequences were conceptually cloned into two different Multiple Cloning Sites of pcDNA3 vector.

Results: We predicted epitopes for both $\mathrm{MHCl}$ and $\mathrm{MHCl}$ which showed the highest binding affinity. Non allergenic and non self epitopes were used to design vaccine. Population coverage analysis showed the vaccine to cover almost all the populations of the world.

Conclusion: The DNA vaccine based on T-Cell epitopes from almost all the PspA variants may prove to be immunogenic and provide protection against $S$. pneumoniae infection.

No conflict of interest 
ISPPD-0290

Next Generation Vaccines

\section{DEVELOPMENT OF A FORMULATION PROCESS FOR CUBAN HEPTAVALENT PNEUMOCOCCAL CONJUGATE VACCINE}

Y. Valdés-Balbín ${ }^{1}$, Y. Serrano-Rodríguez ${ }^{2}$, A. Perez-Baños ${ }^{1}$, L. Nadal-Becerra ${ }^{3}$, D. Santana-Medero ${ }^{2}$, A. Villar-Aneiros $^{3}$, Y. Martin-García ${ }^{1}$, D. García-Rivera ${ }^{1}$, V. Vérez-Bencomo ${ }^{1}$

${ }^{1}$ Immunology, Center for Biomolecular Chemistry, Havana, Cuba; ${ }^{2}$ Glycobiology, Center for Biomolecular Chemistry, Havana, Cuba; ${ }^{3}$ Glycotechnology, Center for Biomolecular Chemistry, Havana, Cuba

A heptavalent conjugate vaccine against pneumococcus is actually in clinical evaluation in Cuba. The vaccine candidate includes the seven serotypes more frequently reported in Latin America; 1, 5, 6B, 14, 18C, 19F and $23 \mathrm{~F}$ bounded to tetanus toxoid as carrier protein and adsorbed to AlPO4 as adjuvant. An important issue in the development of such combine vaccine is the development of adequate formulation. We will discuss the adjuvation step and the effect of adjuvant in the immunological response. We elaborate a methodology for finding optimum parameters as temperature, $\mathrm{pH}$, time and concentration for each serotype. The conditions found were further used for product adjuvation. The impact of the adjuvant was evaluated in mice (Sp 1, 14, 18C and 19F) and rabbits (Sp 5, 6B and 23F) using a schedule of three doses. In general, we observed different on the number of animalsresponders and the immunogenicity after second doses. From the above results, the procedure for formulating the multivalent vaccines was established that includes three steps: combination, adjuvation and final dilution. The process proved to be accurate under GMP conditions for producing batches containing thousands of doses. Their use in clinical trials will be reported in a separate communication.

Conflict of interest 